\title{
Article \\ Investigation of the Effects of Rapid Thermal Annealing on the Electron Transport Mechanism in Nitrogen-Doped ZnO Thin Films Grown by RF Magnetron Sputtering
}

\author{
Simeon Simeonov ${ }^{1}$, Anna Szekeres ${ }^{1, *(\mathbb{D})}$, Dencho Spassov ${ }^{1}$, Mihai Anastasescu ${ }^{2} \mathbb{D}$, Ioana Stanculescu ${ }^{3,4} \mathbb{D}$,

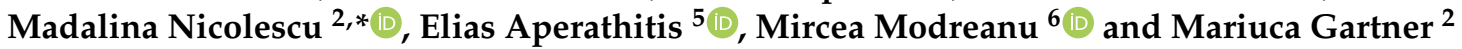 \\ 1 Institute of Solid State Physics, Bulgarian Academy of Sciences, 72 Tsarigradsko Chaussee, \\ 1784 Sofia, Bulgaria; simeon@issp.bas.bg (S.S.); d_spassov@abv.bg (D.S.) \\ 2 Institute of Physical Chemistry "Ilie Murgulescu", Romanian Academy, 202 Splaiul Independentei, \\ 060021 Bucharest, Romania; manastasescu@icf.ro (M.A.); mgartner@icf.ro (M.G.) \\ 3 Horia Hulubei National Institute of Research and Development for Physics and Nuclear Engineering, \\ 30 Aleea Reactorului, 077125 Magurele, Romania; istanculescu@nipne.ro \\ 4 Department of Physical Chemistry, Faculty of Chemistry, University of Bucharest, 4-12 Regina Elisabeta Bd., \\ 030018 Bucharest, Romania \\ 5 Microelectronics Research Group, Institute of Electronic Structure and Laser, Foundation for Research and \\ Technology (FORTH-Hellas), P.O. Box 1385, 70013 Heraklion, Crete, Greece; eaper@physics.uoc.gr \\ 6 Tyndall National Institute, University College Cork, Lee Maltings, Dyke Parade, T12 R5CP Cork, Ireland; \\ mircea.modreanu@tyndall.ie \\ * Correspondence: szekeres@issp.bas.bg (A.S.); mnicolescu@icf.ro (M.N.); \\ Tel.: +40-21-316-79-12 (ext. 588) (M.N.) \\ check for
} updates

Citation: Simeonov, S.; Szekeres, A.; Spassov, D.; Anastasescu, M.; Stanculescu, I.; Nicolescu, M.; Aperathitis, E.; Modreanu, M.; Gartner, M. Investigation of the Effects of Rapid Thermal Annealing on the Electron Transport Mechanism in Nitrogen-Doped ZnO Thin Films Grown by RF Magnetron Sputtering. Nanomaterials 2022, 12, 19. https:// doi.org/10.3390/nano12010019

Academic Editors: Christian Mitterer and Aurora Rizzo

Received: 30 October 2021

Accepted: 18 December 2021

Published: 22 December 2021

Publisher's Note: MDPI stays neutral with regard to jurisdictional claims in published maps and institutional affiliations.

Copyright: (C) 2021 by the authors. Licensee MDPI, Basel, Switzerland. This article is an open access article distributed under the terms and conditions of the Creative Commons Attribution (CC BY) license (https:// creativecommons.org/licenses/by/ $4.0 /)$.

\begin{abstract}
Nitrogen-doped $\mathrm{ZnO}(\mathrm{ZnO}: \mathrm{N})$ thin films, deposited on $\mathrm{Si}(100)$ substrates by RF magnetron sputtering in a gas mixture of argon, oxygen, and nitrogen at different ratios followed by Rapid Thermal Annealing (RTA) at $400{ }^{\circ} \mathrm{C}$ and $550{ }^{\circ} \mathrm{C}$, were studied in the present work. Raman and photoluminescence spectroscopic analyses showed that introduction of $\mathrm{N}$ into the $\mathrm{ZnO}$ matrix generated defects related to oxygen and zinc vacancies and interstitials. These defects were deep levels which contributed to the electron transport properties of the $\mathrm{ZnO}: \mathrm{N}$ films, studied by analyzing the current-voltage characteristics of metal-insulator-semiconductor structures with ZnO:N films, measured at 298 and $77 \mathrm{~K}$. At the appliedtechnological conditions of deposition and subsequent RTA at $400{ }^{\circ} \mathrm{C}$ n-type $\mathrm{ZnO}: \mathrm{N}$ films were formed, while RTA at $550{ }^{\circ} \mathrm{C}$ transformed the n-ZnO:N films to $\mathrm{p}-\mathrm{ZnO}: \mathrm{N}$ ones. The charge transport in both types of $\mathrm{ZnO}: \mathrm{N}$ films was carried out via deep levels in the $\mathrm{ZnO}$ energy gap. The density of the deep levels was in the order of $10^{19} \mathrm{~cm}^{-3}$. In the temperature range of 77-298 K, the electron transport mechanism in the ZnO:N films was predominantly intertrap tunneling, but thermally activated hopping also took place.
\end{abstract}

Keywords: RF magnetron sputtering; ZnO:N thin films; Raman spectroscopy; photoluminescence spectroscopy; electrical characteristics; charge carrier transport properties

\section{Introduction}

Zinc oxide possesses remarkable optical and semiconductor properties, such as a direct wide gap around $3.3 \mathrm{eV}$ at room temperature and a large exciton binding energy of about $60 \mathrm{meV}$ [1]. Because of these properties, $\mathrm{ZnO}$ has huge prospects in applications such as optoelectronic devices [2], homojunction LEDs [3,4], solar cells [5], sensors [6,7], and other devices and structures. However, the use of $\mathrm{ZnO}$ films in these applications requires the ability to control the majority-carrier type and concentration. An asymmetry exists between $\mathrm{n}$ - and p-type doping of $\mathrm{ZnO}$ thin films. While it is possible to prepare stable n-type $\mathrm{ZnO}$ films even without the introduction of donor dopants during the $\mathrm{ZnO}$ film deposition, obtaining p-type $\mathrm{ZnO}$ film requires thermal activation of acceptor dopants incorporated into the $\mathrm{ZnO}$ film during its deposition [8]. In some cases, an additional 
problem is the subsequent transformation of the p-type $\mathrm{ZnO}$ films into n-type $\mathrm{ZnO}$ films [9]. This is why producing stable and qualitative p-type $\mathrm{ZnO}$ films is still a challenge facing the technologies of the above-listed devices and structures.

Much effort has been made to obtain p-type $\mathrm{ZnO}$ films by applying different advanced deposition methods [10-14] and introducing different elements into $\mathrm{ZnO}$ as additives [15]. Among the acceptor dopants, nitrogen is considered themost promising [9]. The nitrogen atom possesses three $2 p$ valence electrons, while the oxygen atom has four $2 p$ valence electrons. The size of the nitrogen atom and the energy of the $\mathrm{N} 2 \mathrm{p}$ valence electrons are closest to the corresponding values of the oxygen atom [16]. Therefore, one might expect the replacement of some $\mathrm{O}$ anions in the anion sublattice with $\mathrm{N}$ anions and the formation of shallow acceptor levels in the $\mathrm{ZnO}$ energy gap. However, to prepare a stable p-type $\mathrm{ZnO}$ film by $\mathrm{N}$ doping is rather difficult due to the low solubility of nitrogen, and thus the low concentration of holes in the films. Another obstacle to effective p-type doping via the replacement of $\mathrm{O}$ by $\mathrm{N}$ in the anion sublattice is the simultaneous generation of shallow and deep donor-type defects in the $\mathrm{ZnO}$ energy gap, such as oxygen vacancies in the $O$ sublattice, $V_{O}$, and zinc interstitials, $Z n_{i}[17-19]$, which leads to self-compensation of $\mathrm{N}$ acceptors in $\mathrm{ZnO}$ [20]. Difficulties in the preparation of p-type $\mathrm{ZnO}$ films have provoked interest in the studies of $\mathrm{ZnO}$ heterojunctions, mainly $\mathrm{ZnO}-\mathrm{Si}$ heterojunctions. The purpose of these investigations is to expand the applications of $\mathrm{ZnO}$ thin films in photoelectron devices and structures, especially in solar cell structures.

Zinc oxide is also the subject of our research. As a pathway for $\mathrm{ZnO}$ thin film deposition, we applied a radio frequency (RF) magnetron sputtering technique. This deposition technique combines the relative easiness of both nitrogen doping of the growing layers by the simple introduction of $\mathrm{N}_{2}$ into the process chamber with control of the deposition parameters (such as gas pressure, substrate temperature, scattering power, and deposition rate). The ability to precisely maintain these parameters during film deposition determines the reproducibility and efficiency of this method. Because of this, RF magnetron sputtering is one of the most widely used methods for thin-film deposition. In order to improve the properties of our ZnO:N films, we applied postdeposition rapid thermal annealing (RTA) in a nitrogen atmosphere at different temperatures. The choice of RTA was due to the fact that it is more technologically relevant than conventional thermal treatments that take much longer and are more highly energy consuming. Moreover, during the RTA process, nitrogen release from the $\mathrm{ZnO}: \mathrm{N}$ layer is less probable. It has been shown that the RTA method is a particularly suitable method for improving the structural, optical, and electrical properties of $\mathrm{ZnO}$ films [21,22].

In order to use nitrogen-doped $\mathrm{ZnO}$ films in $\mathrm{ZnO}$ homo- and heterojunctions and/or as transparent conductive oxide films, a detailed characterization of their structural, opti$\mathrm{cal}$, and electrical properties is required. It is particularly important to understand, and hence to tailor, the charge transfer processes in these materials. Accordingly, detailed structural studies including X-ray Diffraction (XRD), Transmission Electron Microscopy (TEM), Atomic Force Microscopy (AFM), and Scanning Electron Microscopy (SEM) were preliminarily conducted on the RF-sputtered N-doped $\mathrm{ZnO}$ films [23-25]. We established that RTA treatment in $\mathrm{N}_{2}$ at moderate temperatures essentially improves the crystalline state of the $\mathrm{ZnO}$ films, magnetron sputtered onto crystalline silicon [23], or fused silica [24] substrates, yielding a polycrystalline columnar structure with nanocrystallites of 9-13 nm, preferentially oriented in the (002) direction. In these studies, the $\mathrm{ZnO}$ films were deposited in a gas mixture of $\mathrm{Ar}: \mathrm{O}_{2}: \mathrm{N}_{2}=50: 40: 10$ and at a total pressure of $0.66 \mathrm{~Pa}$ (5 m Torr). Further, we collected the same measurements as mentioned above on $\mathrm{ZnO}$ films deposited under increased amounts of $\mathrm{N}_{2}$ and a constant amount of Ar. It was established that variation of the Ar: $\mathrm{O}_{2}: \mathrm{N}_{2}$ mixture to 50:25:25 and 50:10:40 weakly affected the films' crystallinity and surface morphology (the root-mean-square roughness values being lower than $5 \mathrm{~nm}$ ), but influenced the optical properties [25], and hence alteration in the electrical properties is also expected. 
The main purpose of the present research was to investigate the electrical properties of RF magnetron-sputtered nitrogen-doped $\mathrm{ZnO}$ films and to elucidate the charge transport mechanism in these films. There are few data in the literature concerning the charge carrier transport through $\mathrm{N}$-doped $\mathrm{ZnO}$ films and, peculiarly, the charge transport parameters. For this purpose, we prepared $\mathrm{Al}-\mathrm{ZnO}: \mathrm{N}-\mathrm{Si}-\mathrm{Al}$ structures and their electrical properties were studied in detail. In addition, Raman and Photoluminescence (PL) measurements were carried out, aiming to establish the origin and nature of the deep levels associated with inherent defects in the polycrystalline $\mathrm{ZnO}: \mathrm{N}$ films. This could shed more light on electron transitions and charge carrier transport involving $\mathrm{N}$-induced defective centers. The final goal of the research was elucidation of the electron transport properties of zinc-oxidebased films, which would expand their application area in optoelectronics, for example as transparent $\mathrm{ZnO}: \mathrm{N}$ n-p homojunctions.

\section{Materials and Methods}

\subsection{Film Preparation}

The nitrogen-doped $\mathrm{ZnO}$ thin films were deposited by RF magnetron sputtering employing Nordiko RFG-2500 equipment (Nordiko Technical Service Ltd., Havant, Hampshire, United Kingdom). Commercially available zinc nitride target (Testbourne Ltd., Basingstoke, Hampshire, UK), Zn:N = 1:1, purity $99.9 \%, 6$ in diameter $\times 0.25$ in thick) was sputtered in a gas mixture of $\mathrm{Ar}, \mathrm{O}_{2}$, and $\mathrm{N}_{2}$ onto p-type $\mathrm{Si}(100)$ substrates with specific resistivity over $100 \Omega \mathrm{cm}$. In general, the substrates never occupied an area bigger than $\sim 12 \mathrm{~cm}^{2}$ on the holder. The distance between the target and substrates was $11 \mathrm{~cm}$.

The substrates were ultrasonically cleaned in acetone and isopropanol, rinsed in deionized water, and dried in flowing nitrogen gas. The native oxide on the Si surface was etched in HF solution before the substrates were introduced into the sputtering system. After reaching the base pressure of $1.33 \times 10^{-5} \mathrm{~Pa}\left(10^{-7} \mathrm{~m}\right.$ Torr $)$ and prior to deposition, the target was presputtered for at least $15 \mathrm{~min}$ (Ar plasma, $0.66 \mathrm{~Pa}$ (5 m Torr), $100 \mathrm{~W}$ RF power) to remove any contaminants from the target surface and to enable equilibrium conditions to be reached. The RF power was kept at $100 \mathrm{~W}$. The sputtering was carried out at a total pressure of $0.66 \mathrm{~Pa}\left(5 \mathrm{~m}\right.$ Torr) in a gas mixture of $\mathrm{Ar}: \mathrm{O}_{2}: \mathrm{N}_{2}$, keeping Ar constant at $50 \%$ and varying the ratio of $\mathrm{O}_{2}$ and $\mathrm{N}_{2}$ percentages: (i) $\mathrm{O}_{2}: \mathrm{N}_{2}=40: 10$, (ii) $\mathrm{O}_{2}: \mathrm{N}_{2}=10: 40$, and (iii) $\mathrm{O}_{2}: \mathrm{N}_{2}=25: 25$. During deposition, no external heating was applied to the substrates. At the given technological conditions, the deposition rate of the $\mathrm{ZnO}$ films was $0.83 \mathrm{~nm} / \mathrm{min}$ for the films made in the oxygen-rich plasma and $0.32 \mathrm{~nm} / \mathrm{min}$ for the films made in oxygen-deficient plasma.

After deposition, and following our previous investigations concerning postdeposition annealing conditions as mentioned above [23-25], the $\mathrm{ZnO}: \mathrm{N}$ samples were subjected to RTA at temperatures of $400{ }^{\circ} \mathrm{C}$ and $550{ }^{\circ} \mathrm{C}$ for $1 \mathrm{~min}$ in $\mathrm{N}_{2}$ atmosphere. The annealing temperature of $550{ }^{\circ} \mathrm{C}$ was not exceeded in order to avoid any possible release of nitrogen from the structure of the films [26].

The denotations of the $\mathrm{ZnO}: \mathrm{N}-\mathrm{Si}$ samples prepared under different technological conditions are presented in Table 1. In the table, we have included the thicknesses of the corresponding films, which were determined with an accuracy of $\pm 0.2 \mathrm{~nm}$ from the spectral ellipsometric measurements. The scatter of the as-deposited films' thickness resulted mainly from the low deposition rates and different sputtering durations. It should be pointed out that the thickness uniformity of the films deposited on given Si samples was 96\%, as established by the ellipsometric mapping [25]. 
Table 1. Technological conditions and corresponding sample number of $\mathrm{ZnO}: \mathrm{N}$ films with the given layer's thickness.

\begin{tabular}{cccc}
\hline $\begin{array}{c}\text { ZnO:N Sample } \\
\text { Number }\end{array}$ & $\begin{array}{c}\text { Gas Mixture of } \\
\mathbf{A r}_{\mathbf{O}} \mathbf{O}_{\mathbf{2}}: \mathbf{N}_{\mathbf{2}} \mathbf{( \% )}\end{array}$ & $\begin{array}{c}\text { RTA Temperature } \\
\left({ }^{\circ} \mathbf{C}\right)\end{array}$ & $\begin{array}{c}\text { ZnO:N Film } \\
\text { Thickness (nm) }\end{array}$ \\
\hline 1.1 & & as-deposited & 214.8 \\
1.2 & $50: 40: 10$ & 400 & 183.8 \\
1.3 & & 550 & 185.7 \\
\hline 2.1 & $50: 10: 40$ & as-deposited & 206.6 \\
2.2 & & 400 & 180.7 \\
2.3 & & 550 & 202.2 \\
\hline 3.1 & $50: 25: 25$ & as-deposited & 106.4 \\
3.2 & & 400 & 127.0 \\
3.3 & & 550 & 124.4 \\
\hline
\end{tabular}

The bandgap energy values of $\mathrm{ZnO}: \mathrm{N}$ films deposited under the same technological condition as were used in the present work have been determined from the ellipsometric data analysis published elsewhere [25]. It was found that for the as-deposited $\mathrm{ZnO}: \mathrm{N}$ films, the bandgap energy value was $3.25 \pm 0.025 \mathrm{eV}$, while for the $400{ }^{\circ} \mathrm{C}$ and $550{ }^{\circ} \mathrm{C}$ RTA samples there was a slight reduction toward $3.20 \pm 0.025 \mathrm{eV}$. These optical bandgap energy values are in good agreement with the literature reports $[17,19,27,28]$.

\subsection{Characterization Methods}

Raman scattering spectra of the films were recorded on a complex configuration Bruker Vertex 70 FTIR/FT-Raman instrument (Bruker, Ettlingen, Germany). The spectrometer equipped with a RAM II module using a Nd:YAG laser $(1064 \mathrm{~nm})$ with variable power (1-500 $\mathrm{mW}$ ) and LN2 cooled Ge detector. The Fourier-transform Raman spectra were registered between 200 and $600 \mathrm{~cm}^{-1}$ with 512 scans and $4 \mathrm{~cm}^{-1}$ spectral resolution, and a laser power of $1 \mathrm{~mW}$.

The photoluminescence (PL) measurements were carried out on a Carry Eclipse (Agilent Technologies, Melbourne, Australia), fluorescence spectrometer, with the slits set at $20 \mathrm{~nm}$. The photoluminescence at room temperature was excited by the $325 \mathrm{~nm}$ line from a Xe bulb lamp. The PL spectra were taken with a scan rate of $120 \mathrm{~nm} / \mathrm{min}$ and spectral resolution of $0.5 \mathrm{~nm}$.

The electrical measurements were conducted on metal-ZnO:N-silicon capacitors (further denoted as metal-insulator-semiconductor (MIS) structures) formed by vacuum thermal evaporation of $\mathrm{Al}$ dots with $1.96 \times 10^{-3} \mathrm{~cm}^{2}$ area onto the $\mathrm{ZnO}$ top surface through a metal mask, while continuous $\mathrm{Al}$ film was evaporated as a contact to the silicon backside.

The electrical properties of the MIS structures were examined from the current-voltage (I-V) characteristics, measured in two ways. In the first way, the I-V characteristics were automatically measured at room temperature in a dark chamber using a Keithley $4200 \mathrm{Semi}-$ conductor Characterization System with a ramp rate of $0.1 \mathrm{~V} / \mathrm{s}$. In the second way, the $\mathrm{I}-\mathrm{V}$ curves were measured point by point with a cycle sequence starting from $0 \mathrm{~V}$ toward negative or positive voltages, with maximal amplitude applied to the top Al-dot contact followed by a voltage reversal toward zero voltage. The first measurement cycle starting from zero up to maximal applied voltage, $\mathrm{V}_{\mathrm{a}}$, is denoted further as the initial stage. The duration of each measurement cycle was approximately $20-25 \mathrm{~min}$. This kind of I-V measurement was applied to samples 2.1 and 2.3 at temperatures of 298 and $77 \mathrm{~K}$. In this way, the presence and behavior of deep levels in the $\mathrm{ZnO}: \mathrm{N}$ films could be examined and their concentrations determined.

In addition, the impedance of the MIS structures with $\mathrm{ZnO}$ layers 2.1 and 2.3 was measured at room temperature with a Tesla BM-507 impedance meter (TESLA, Praha, Czechoslovakia) applying test voltage frequencies in the range of $0.5-500 \mathrm{kHz}$. Herein, we consider only the parallel conductance, $G_{m}$, values, calculated from the measured $\left|Z_{m}\right|$ and $\varphi_{\mathrm{m}}$ quantities using the expression $\mathrm{G}_{\mathrm{m}}=\cos \left(\varphi_{\mathrm{m}}\right) /\left|\mathrm{Z}_{\mathrm{m}}\right|$. 


\section{Results and Discussion}

The structural and morphological properties of the $\mathrm{ZnO}: \mathrm{N}$ films (Table 1), as well as their chemical compositions, were reported in our previous papers [23-25]. XRD investigations revealed that all $\mathrm{ZnO}: \mathrm{N}$ films were crystallized in a hexagonal $\mathrm{ZnO}$ wurtzite phase (JCPDS data card 36-1451), (002) oriented, and exhibited an improvement in crystallinity after RTA. There was no noticeable change in the XRD patterns induced by the variation of the nitrogen content in the sputtering reactor atmosphere during $\mathrm{ZnO}: \mathrm{N}$ film deposition, but the values of the crystallite size, estimated using the Scherrer formula, increased with the RTA temperature and with $\mathrm{N}_{2}$ content in the sputtering atmosphere, from $14.4 \mathrm{~nm}$ $\left(10 \% \mathrm{~N}_{2}\right)$ to $15.7 \mathrm{~nm}\left(40 \% \mathrm{~N}_{2}\right)$ for the $\mathrm{ZnO}: \mathrm{N}$ films after RTA at $550{ }^{\circ} \mathrm{C}$ [25]. From a topographic point of view, all ZnO:N-Si samples (Table 1) showed a homogeneous distribution of small and rounded superficial grains, with an average diameter in the range of 40-70 nm, all surfaces being smooth, with a root-mean-square (RMS) roughness of lessthan $5 \mathrm{~nm}$. From TEM investigations, it was found that the morphology of the $\mathrm{ZnO}: \mathrm{N}$ films was columnar, with the grain column axis oriented nearly parallel with the hexagonal $<001>$ axis of the $\mathrm{ZnO}$ structure. The columnar structures had variable diameters from $10 \mathrm{~nm}$ at the bottom to $50 \mathrm{~nm}$ at the top (for the films sputtered under $40 \%$ nitrogen), so that the surface had larger grains which were well faceted, as seen by AFM. The columns of the as-deposited films contained a lot of defects and pores which diminished after RTA. The presence of the nitrogen inside the $\mathrm{ZnO}: \mathrm{N}$ films was not detected by XRD analysis due to its very small amount, but was evidenced in Energy-dispersive X-ray spectroscopy (EDX) observations conducted in a ratio of 1/6 (nitrogen/oxygen) for the films deposited on $\mathrm{Si}$, regardless of the RTA treatment. However, the presence of nitrogen was clearly pointed out by X-ray photoelectron spectroscopy (XPS) in the RTA samples only as zinc nitride and diluted zinc oxynitride, as reported previously [23,24]. Nevertheless, the uniformity of thickness deposition, determined by ellipsometric mapping, was found to be around $96 \%$ for the $\mathrm{ZnO}: \mathrm{N}$ films deposited on silicon [25].

\subsection{Analysis of FT-Raman Spectra}

In Figure 1, as a representative illustration, the Raman spectra of the $\mathrm{ZnO}: \mathrm{N}$ film deposited in gas mixture of $\mathrm{Ar}: \mathrm{O}_{2}: \mathrm{N}_{2}=50: 10: 40$, (sample 2.1) and RT annealed at $550{ }^{\circ} \mathrm{C}$ (sample 2.3) are given. The nonsymmetrical shape of the Raman peaks is due to the multiple contributions from the polycrystalline nature of the $\mathrm{ZnO}: \mathrm{N}$ [25]. The vibrational bands of $\mathrm{Si}-\mathrm{Si}$ bonds are also indicated, appearing as a strong peak at $523 \mathrm{~cm}^{-1}$ and as a weak and broad peak in the $303-308 \mathrm{~cm}^{-1}$ spectral range. The kind and position of the observed vibrational modes of $\mathrm{ZnO}: \mathrm{N}$ films in dependence on the oxygen/nitrogen content and RTA temperature are summarized in Table 2.

Pure, crystalline $\mathrm{ZnO}$ has eight sets of optical phonon modes at the $\Gamma$ point in the Brillouin zone, $\Gamma_{\text {opt }}$, expressed as $\Gamma_{\text {opt }}=A_{1}+E_{1}(I R, R)+2 E_{2}(R)+2 B_{1}[29]$. The $A_{1}$ and $E_{1}$ modes are both Raman and infrared active and split into transverse optical (TO) and longitudinal optical (LO) phonon modes. The $\mathrm{E}_{2}$ modes are Raman active and nonpolar at low$\left(\mathrm{E}_{2}{ }^{(\mathrm{low})}\right)$ and high-frequency $\left(\mathrm{E}_{2}{ }^{(\mathrm{high})}\right.$ ) phonon modes. The $\mathrm{E}_{2}{ }^{(\mathrm{low})}$ mode involves mainly Zn sublattice motion while $E_{2}($ high) is associated with the vibration of oxygen atoms [30]. There are also two $B_{1}$ modes, $B_{1}{ }^{(l o w)}$ and $B_{1}{ }^{(h i g h)}$, which are inactive Raman modes but can be activated by introducing defects or by doping with other elements [29,31,32].

The recorded FT-Raman spectra exhibited the state of molecular $\mathrm{Zn}-\mathrm{O}$ bonds in the $\mathrm{ZnO}: \mathrm{N}$ films under changing technological conditions. The increase of the peaks' intensity after RTA treatment implies the increase of defects related to $\mathrm{O}$ and $\mathrm{Zn}$ vacancies and interstitials. The bands that appeared at $230-240 \mathrm{~cm}^{-1}$ and $330 \mathrm{~cm}^{-1}$ correspond to $\left(2 \mathrm{TA}\right.$ and $\left.2 \mathrm{E}_{2}{ }^{(\mathrm{low})}\right)$ and $\mathrm{E}_{2}{ }^{\text {(high) }}-\mathrm{E}_{2}{ }^{(\mathrm{low})}$, respectively, and are assigned to the contribution of second-order vibrations, two-phonon modes which become activated in thin films. The peak around $377 \mathrm{~cm}^{-1}$ was identified as the $\mathrm{A}_{1}(\mathrm{TO})$ mode, which indicates the displacement of $\mathrm{Zn}^{2+}$ and $\mathrm{O}^{2-}$ ions parallel to the c-axis, near the center of the Brillouin zone ( $\Gamma$ point) $[30,33,34]$. In comparison to the pure crystalline $\mathrm{ZnO}$, the position of the wide 
$\mathrm{E}_{2}$ (high) peak at $410-420 \mathrm{~cm}^{-1}$ was significantly shifted in the doped $\mathrm{ZnO}: \mathrm{N}$ films, indicating that nitrogen doping mainly affected the oxygen bonds. The peak at $550 \mathrm{~cm}^{-1}$ was assigned to the inactive $\mathrm{A}_{1}(\mathrm{LO})$ mode, activates by introducing defects or by doping with other elements [25,31-33]. The observed peak at $590 \mathrm{~cm}^{-1}$ was attributed to the $\mathrm{E}_{1}(\mathrm{LO})$ mode that appeared due to oxygen vacancies $V_{O}$, zinc interstitials $Z n_{i}$, and free carriers $[35,36]$ existing in the analyzed $\mathrm{ZnO}$ films. The Raman study proved that the incorporation of nitrogen into the films caused disordering of the $\mathrm{ZnO}$ lattice. Considering that the spectra were taken with a resolution of $4 \mathrm{~cm}^{-1}$, the close positions of the corresponding peaks indicated similar structure and chemical bonding. The exceptions were the peaks around $402-412 \mathrm{~cm}^{-1}$, confirming that the change in the oxygen/nitrogen ratio in the Ar: $\mathrm{O}_{2}: \mathrm{N}_{2}$ mixture predominantly affectedthe oxygen bonds in the $\mathrm{ZnO}$ lattice.

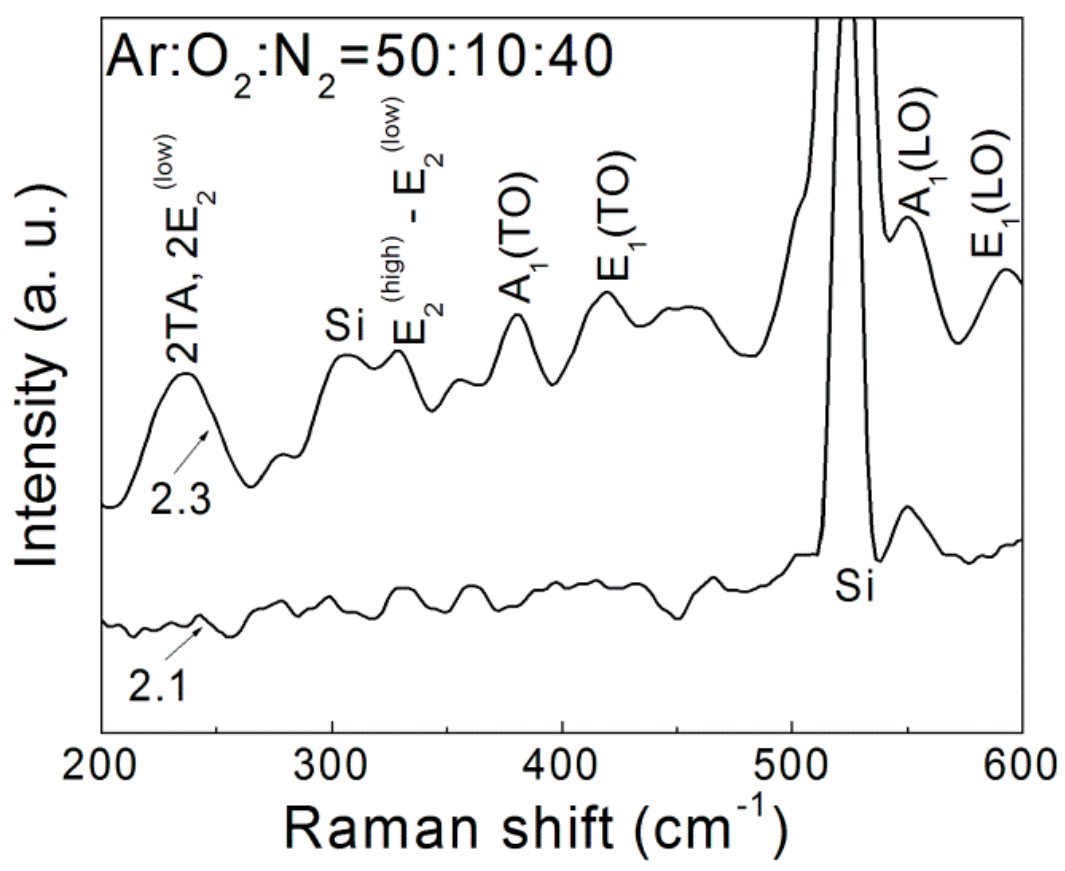

Figure 1. Representative Raman spectra of $\mathrm{ZnO}: \mathrm{N}$ films, deposited in a gas mixture of Ar: $\mathrm{O}_{2}: \mathrm{N}_{2}=50: 10: 40$ (sample 2.1) and after RTA at $550{ }^{\circ} \mathrm{C}$ (sample 2.3).

Table 2. Position of the Raman phonon modes in the $\mathrm{ZnO}: \mathrm{N}$ thin films.

\begin{tabular}{|c|c|c|c|c|c|c|c|}
\hline \multirow{4}{*}{$\begin{array}{c}\text { Gas Ratio of } \mathbf{A r}: \mathrm{O}_{2}: \mathbf{N}_{\mathbf{2}}(\mathbf{\%}) \\
50: 40: 10\end{array}$} & \multirow{4}{*}{$\begin{array}{c}\text { RTA Temperature } \\
\left({ }^{\circ} \mathbf{C}\right)\end{array}$} & \multicolumn{6}{|c|}{$\begin{array}{l}\text { Raman Molecular Vibration Modes } \\
\qquad\left(\mathrm{cm}^{-1}\right)\end{array}$} \\
\hline & & 221 & 332 & 373 & 411 & 555 & 589 \\
\hline & & 224 & 338 & 377 & 415 & 555 & 590 \\
\hline & & 234 & 334 & 378 & 409 & 557 & 595 \\
\hline \multirow{3}{*}{$50: 25: 25$} & as-deposited & 237 & 336 & 376 & 412 & 553 & 594 \\
\hline & 400 & 233 & 329 & 372 & 402 & 552 & 590 \\
\hline & 550 & 236 & 330 & 376 & 418 & 551 & 593 \\
\hline \multirow{3}{*}{$50: 10: 40$} & as-deposited & 236 & 330 & 376 & 402 & 552 & 593 \\
\hline & 400 & 238 & 335 & 375 & 407 & 554 & 591 \\
\hline & 550 & 239 & 337 & 376 & 411 & 550 & 595 \\
\hline
\end{tabular}

\subsection{Photoluminescence Analysis}

In general, in the PL spectra of $\mathrm{ZnO}$ films, two emission bands can be observed: one is in the UV region within the 361-369 $\mathrm{nm}$ range and the second band is in the visible range of $450-550 \mathrm{~nm}[32,37]$. As the excitation source (Xe bulb lamp) was not intense enough to 
excite the transitions associated with the optical band gap energy, the first characteristic band was not observed. In Figure 2, typical PL spectra in the spectral range of 400-560 nm are presented for a $\mathrm{ZnO}: \mathrm{N}$ film deposited in gas mixture of $\mathrm{Ar}: \mathrm{O}_{2}: \mathrm{N}_{2}=50: 10: 40$ (sample 2.1) and after RTA annealing at $550{ }^{\circ} \mathrm{C}$ (sample 2.3).
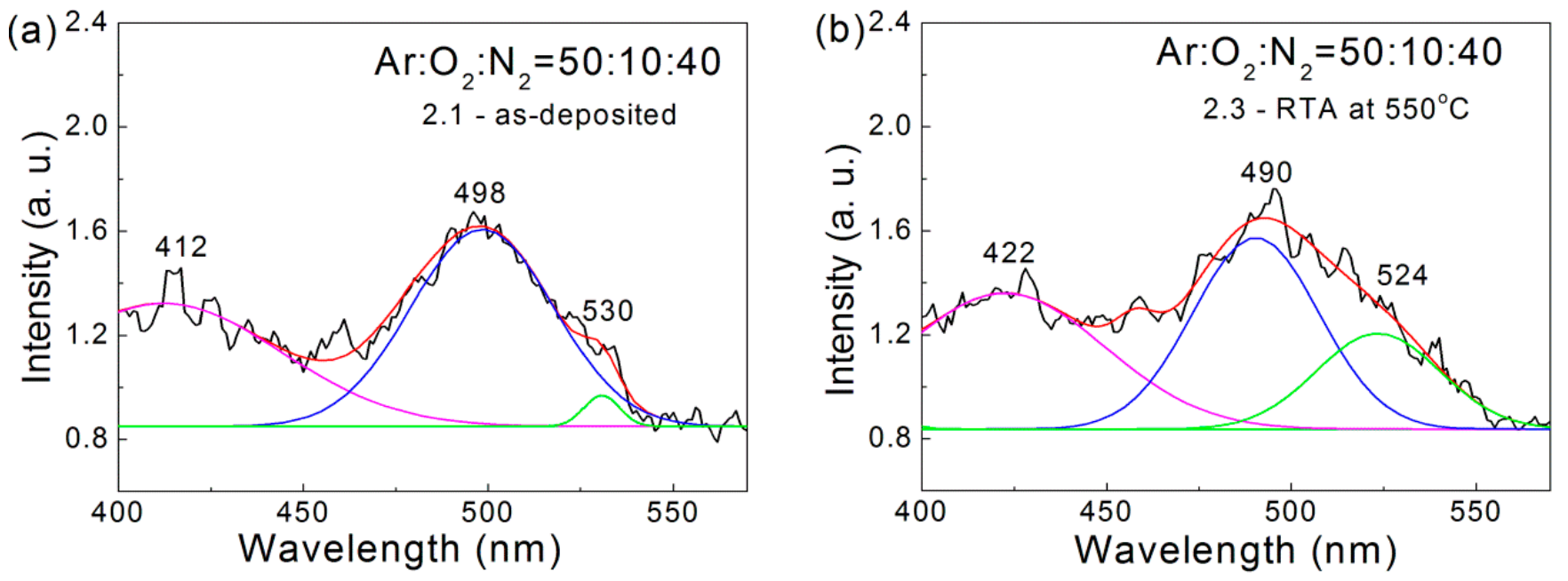

Figure 2. Representative PL spectra of the $\mathrm{ZnO}: \mathrm{N}$ films deposited in a gas mixture of Ar: $\mathrm{O}_{2}: \mathrm{N}_{2}=$ 50:10:40: (a) as-deposited (sample 2.1) and (b) after RTA at $550{ }^{\circ} \mathrm{C}$ (sample 2.3).

The representative PL spectra of the studied $\mathrm{ZnO}: \mathrm{N}$ films were characterized by a weak band around 455-460 $\mathrm{nm}$ and more strong and broad bands around $412 \mathrm{~nm}$ and $500 \mathrm{~nm}$. Due to the broad PL peaks, their locations were difficult to resolve accurately. For this reason, we tried to find the Gaussian components until the best fit was achieved. The dominant $500 \mathrm{~nm}$ band was deconvoluted into two Gaussian components as the peaks were situated around 490 and $524 \mathrm{~nm}$.

The emission peak from the band-to-band recombinations was expected to appear around $382 \mathrm{~nm}$, the wavelength corresponding to the bandgap energy $(3.25 \pm 0.025 \mathrm{eV})$ of our $\mathrm{ZnO}$ films. However, in the measured PL spectra, the emission peak was centered within the 410-420 nm region, and hence it originated most probably from defect states close to the $\mathrm{ZnO}$ bandgap edges. Previous research suggests that zinc interstitial defects, $\mathrm{Zn}_{\mathrm{i}}$, creating shallow states underneath the conduction band edge, are a possible reason for the appearance of this PL peak [38]. The emission peak at $\sim 490 \mathrm{~nm}(2.53 \mathrm{eV})$ was a typical blue green emission of $\mathrm{ZnO}$, which may be attributed to a high density of point defects such as zinc vacancy, $\mathrm{V}_{\mathrm{Zn}}$, oxygen vacancy, $\mathrm{V}_{\mathrm{O}}$, and interstitial oxygen, $\mathrm{O}_{\mathrm{i}}$, in the polycrystalline structure of $\mathrm{ZnO}$ [39]. The green emission peak at $\sim 525 \mathrm{~nm}(2.36 \mathrm{eV})$ resulted from radiative recombination of holes with electrons at the singly ionized intrinsic oxygen vacancies $[40,41]$. These kinds of defects are deep levels, which contribute to the electron transport properties and were considered further at the data analysis of electrical measurements.

The positions of emission peaks obtained by Gaussian deconvolution of the PL spectra of $\mathrm{ZnO}: \mathrm{N}$ films are summarized in Table 3. It can be observed that for the as-deposited films, the increase of the nitrogen content from 10 to $40 \%$ resulted in a shift of the Gaussian peaks' position from $493 \mathrm{~nm}$ and $524 \mathrm{~nm}$ to $498 \mathrm{~nm}$ and $530 \mathrm{~nm}$, respectively. This could be attributed to the increased defect generation and disordering of the ZnO lattice by nitrogen doping, as detected by the Raman measurements above. During heat treatment, these defects were partially annealed and, as a consequence, the Gaussian peaks moved to smaller wavelengths with increasing RTA temperature. 
Table 3. The positions of the PL Gaussian emission peaks of the ZnO:N films.

\begin{tabular}{cccc}
\hline $\begin{array}{c}\text { Gas Ratio of } \\
\text { Ar: } \mathbf{O}_{\mathbf{2}}: \mathbf{N}_{\mathbf{2}} \\
\mathbf{( \% )}\end{array}$ & RTA Temperature $\left({ }^{\circ} \mathbf{C}\right)$ & $\begin{array}{c}\text { Blue Green } \\
\text { Spectral Range } \\
(\mathbf{n m})\end{array}$ & $\begin{array}{c}\text { Green } \\
\text { Spectral Range } \\
(\mathbf{n m})\end{array}$ \\
\hline \multirow{2}{*}{$50: 40: 10$} & as-deposited & 493 & 524 \\
& 400 & 497 & 522 \\
$50: 25: 25$ & 550 & 497 & 525 \\
& as-deposited & 495 & 527 \\
& 400 & 495 & 523 \\
$50: 10: 40$ & 550 & 495 & 522 \\
& as-deposited & 498 & 530 \\
& 400 & 496 & 525 \\
\hline
\end{tabular}

The above Raman and PL measurements show that inherent structural defects and $\mathrm{N}$-induced defect centers were present in the $\mathrm{ZnO}$ films. These can be associated with localized states in the energy gap of $\mathrm{ZnO}$, which are traps for electric charge carriers. For example, it has been established that the dominant defect centers of oxygen vacancy (PL peak at $\sim 492 \mathrm{~nm}$ ) develop deep energetic levels of $1.4 \mathrm{eV}$ for electrons and $1.6 \mathrm{eV}$ for holes in the $\mathrm{ZnO}$ bandgap [42].

\subsection{Electric Charge Transport Properties}

In order to prove the role of deep levels in the conduction mechanism and to study the current via these deep levels, we conducted a detailed study of the I-V characteristics of the MIS structures formed with the $\mathrm{ZnO}: \mathrm{N}$ films. The I-V characteristics of the MIS structures with the $\mathrm{ZnO}: \mathrm{N}$ films, automatically recorded at room temperature, are summarized in Figure 3. A schematic representation of the studied MIS structures is shown as the lower left inset in Figure 3a.
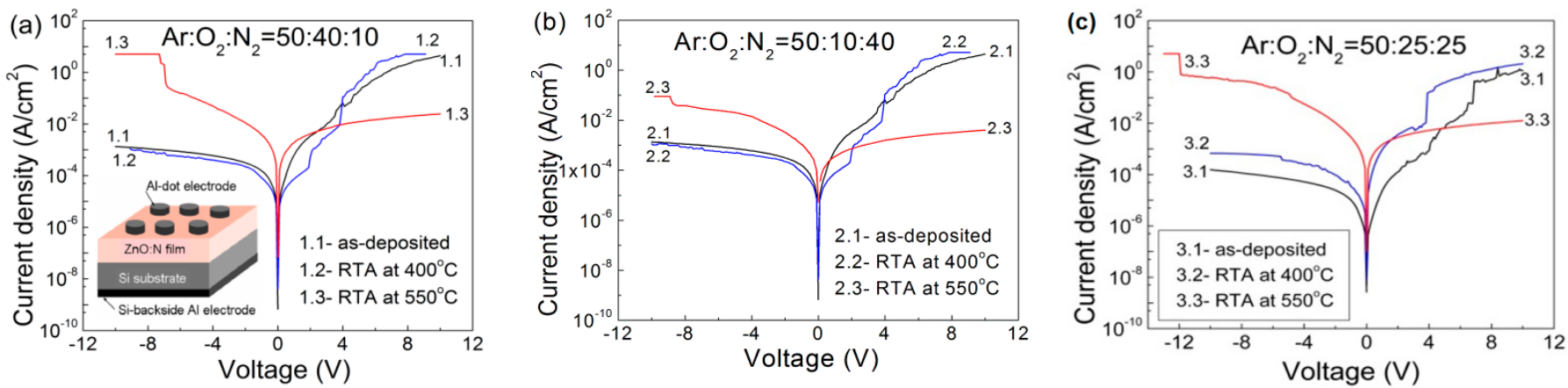

Figure 3. Automatically recorded I-V characteristics of MIS structures with ZnO:N films, deposited at different gas ratios: $\mathrm{Ar}: \mathrm{O}_{2}: \mathrm{N}_{2}=50: 40: 10$ (a), Ar: $\mathrm{O}_{2}: \mathrm{N}_{2}=50: 10: 40$ (b), and Ar: $\mathrm{O}_{2}: \mathrm{N}_{2}=50: 25: 25$ (c). The corresponding sample numbers are given in the insets. The lower left inset in (a) shows the schematic structure of the measured samples.

In the case of as-deposited $\mathrm{ZnO}: \mathrm{N}$ films (samples 1.1, 2.1, and 3.1) and those after RTA treatment at $400{ }^{\circ} \mathrm{C}$ (samples 1.2, 2.2 and 3.2), the current at positive voltages applied to the top Al-dot electrode was higher than the current in the case of negative voltage applied to the same contact. These MIS structures had diode-like properties. At absolute voltages of 8-10 V, the rectification ratios were $\sim 4600,7055$, and 2500 for the as-deposited films obtained at $10 \%, 25 \%$, and $40 \% \mathrm{~N}_{2}$ in the gas mixture, respectively. This ratio decreased after $400{ }^{\circ} \mathrm{C}$ RTA but still remained in the order of $10^{3}$. The strongest rectification effect was observed in $\mathrm{ZnO}: \mathrm{N}$ films grown at $25 \% \mathrm{~N}_{2}$ in the gas mixture. The existence of asymmetry between the currents at positive and negative voltage values confirms the formation of 
$\mathrm{n}-\mathrm{ZnO}-\mathrm{p}-\mathrm{Si}$ heterojunction. From these observations, it follows that the nitrogen-doped $\mathrm{ZnO}$ films were initially n-type and remained n-type after $400{ }^{\circ} \mathrm{C}$ annealing. In the case of the films deposited at gas ratios of Ar: $\mathrm{O}_{2}: \mathrm{N}_{2}=50: 40: 10$ and $\mathrm{Ar}: \mathrm{O}_{2}: \mathrm{N}_{2}=50: 25: 25$, the comparison of the measured I-V curves of the as-deposited $\mathrm{ZnO}: \mathrm{N}$ films with those of the corresponding ones after RTA at $400{ }^{\circ} \mathrm{C}$ showed close current values, which suggests similar concentrations of the $\mathrm{N}$ dopants.

For the samples after RTA at $550{ }^{\circ} \mathrm{C}$ (Figure 3, samples 1.3, 2.3, and 3.3), the current through the $\mathrm{ZnO}$ film was higher when negative voltage was applied to the top Al-dot electrode. The asymmetry between the currents at positive and negative voltage values was less pronounced, which was expressed in considerably smaller rectification ratios. At absolute voltages of 8-10 V, their values were 230,534 , and 24 for the films deposited at $10 \%, 25 \%$, and $40 \% \mathrm{~N}_{2}$ in the gas mixture, respectively. These results imply that RTA at $550{ }^{\circ} \mathrm{C}$ transformed the nitrogen-doped $\mathrm{ZnO}$ films to p-type $\mathrm{ZnO}$ ones. In accordance with the Anderson heterojunction rule, the $\mathrm{ZnO}$ valence band offset at the $\mathrm{p}-\mathrm{ZnO}-\mathrm{p}-\mathrm{Si}$ was close to $2.6 \mathrm{eV}$ [17]. Because of this valence band offset, the contribution of holes in the $\mathrm{p}$-Si to the forward current in the $\mathrm{p}-\mathrm{ZnO}-\mathrm{p}-\mathrm{Si}$ MIS structure was negligible. Therefore, the forward current in these films was accompanied by electron-hole generation at the $\mathrm{p}-\mathrm{ZnO}-\mathrm{p}-\mathrm{Si}$ interface.

It is known that acceptor dopants introduced into $\mathrm{ZnO}$ films are self-compensated by donor localized states generated in the $\mathrm{ZnO}$ lattice during the dopants' incorporation in $\mathrm{ZnO}[20,43]$. From the results in Figure 3, we can conclude that during RTA at $550{ }^{\circ} \mathrm{C}$, the concentration of donor-like defects decreased in the $\mathrm{ZnO}: \mathrm{N}$ films in such a way that the concentration of nitrogen-acceptor states exceeded that of the remaining donor-like defects. As a result, the n-type as-deposited $\mathrm{ZnO}: \mathrm{N}$ film was transformed to a p-type one during $550{ }^{\circ} \mathrm{C}$ RTA. The I-V characteristics of the same MIS structures, measured after a year, showed only minor changes and still exhibited p-type conductivity in these $\mathrm{ZnO}: \mathrm{N}$ films. Therefore, the transformation of n-type $\mathrm{ZnO}$ film into p-type by $550{ }^{\circ} \mathrm{C} \mathrm{RTA}$ treatment is a stable process.

The transformation of ZnO:N film from n-type to p-type by $550{ }^{\circ} \mathrm{C}$ RTA is similar to the appearance of p-type regions in $\mathrm{N}$-implanted $\mathrm{ZnO}$ single crystals after annealing at $500{ }^{\circ} \mathrm{C}$, observed by deep-level transient spectroscopy (DLTS) measurements [44]. Similar transformations of $\mathrm{N}$-implanted $\mathrm{n}$-type $\mathrm{ZnO}$ films to $\mathrm{p}$-type ones have been observed after RTA treatment at $900{ }^{\circ} \mathrm{C}$ [45].

The current densities in the $\mathrm{ZnO}: \mathrm{N}$ films deposited with nitrogen contents of 10 and $25 \%$ in the vacuum chamber were similar (Figure 3). Deposition of $\mathrm{ZnO}: \mathrm{N}$ films at the highest nitrogen content of $40 \%$ resulted in lower current density, and it remained lower in comparison to the other $\mathrm{ZnO}: \mathrm{N}$ films even after RTA treatment at $550{ }^{\circ} \mathrm{C}$. This result is a consequence of already mentioned self-compensation of acceptor dopants by the simultaneously created donor-like deep levels during the acceptor doping of $\mathrm{ZnO}$.

In $\mathrm{ZnO}$ films doped with nitrogen, the n-type conduction can be attributed to donors formed by interstitial zinc, $\mathrm{Zn}_{\mathrm{i}}$, and oxygen vacancies, $\mathrm{V}_{\mathrm{O}}$, whereas the p-type conduction can be related to the acceptors formed by zinc vacancies, $\mathrm{V}_{\mathrm{Zn}}$, oxygen interstitial, $\mathrm{O}_{\mathrm{i}}$, and nitrogen substituting oxygen in the $O$ sublattice $[18,46,47]$. We have confirmed the presence of these kinds of defect states in ZnO:N films by the analysis of IRSE and FTIR spectra [25] and also by the Raman and PL spectroscopic results presented and discussed above in Sections 3.1 and 3.2.

The specific resistivity, $\rho(V)$, values of the $\mathrm{ZnO}$ films were calculated from the I-V characteristics shown in Figure 3 , in the forward direction with accumulation conditions at the $\mathrm{ZnO}-\mathrm{p}$-Si interface, using the relations $\mathrm{R}_{\text {dif }}=\mathrm{dV} / \mathrm{dI}$ and $\rho(\mathrm{V})=\mathrm{R}_{\mathrm{dif}} \mathrm{S} / \mathrm{d}_{\mathrm{f}}$, where $\mathrm{R}_{\text {dif }}$ is the differential resistance, $d_{f}$ is the film thickness, and $S$ is the Al-dot contact area. The obtained $\rho(\mathrm{V})$ values for the studied $\mathrm{ZnO}: \mathrm{N}$ films are summarized in Figure 4. 

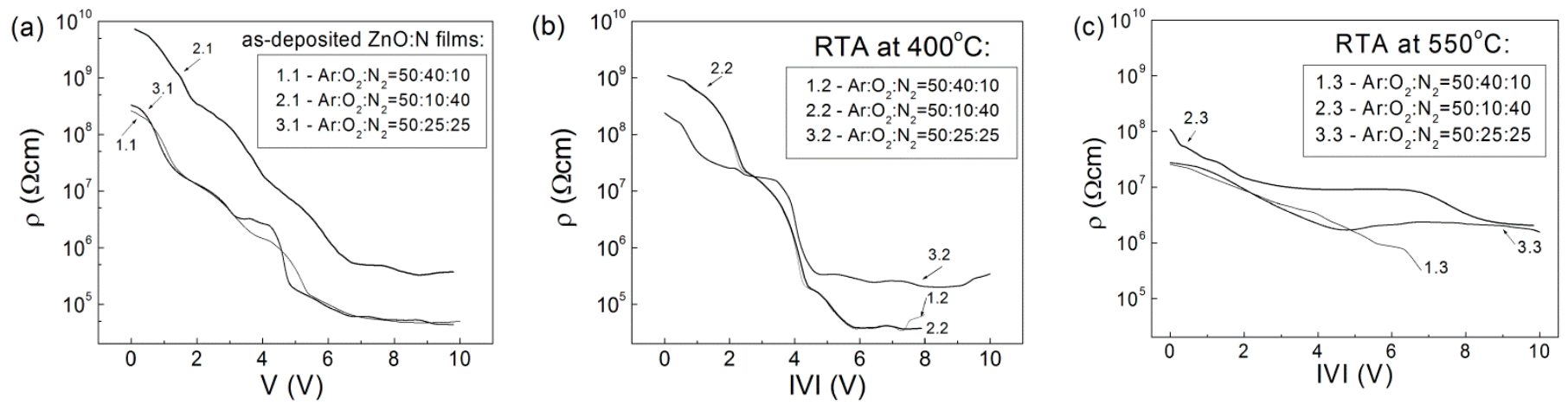

Figure 4. Specific resistivity $\rho(\mathrm{V})$ versus applied forward voltage of $\mathrm{ZnO}: \mathrm{N}$ films (deposited at different gas ratios (a) and after RTA at $400{ }^{\circ} \mathrm{C}(\mathbf{b})$ and $550{ }^{\circ} \mathrm{C}(\mathbf{c})$. The $\rho$ values were calculated from the forward I-V curves shown in Figure 3.

For the as-deposited and $400{ }^{\circ} \mathrm{C}$ RTA n-ZnO:N films (Figure 4a,b), the specific resistivity decreased sharply by more than four orders of magnitude upon increasing the applied voltage from 1 to $8 \mathrm{~V}$. After $550^{\circ} \mathrm{C}$ RTA (Figure $4 \mathrm{c}$ ), the $\rho(\mathrm{V})$ values of the p-ZnO:N films decreased more gradually, as the reduction was approximately two orders of magnitude in the same voltage interval of $1-8 \mathrm{~V}$, but as a whole, they remained above the range of $10^{6} \Omega \mathrm{cm}$. In comparison with the as-deposited $\mathrm{ZnO}: \mathrm{N}$ films, the smaller change of the specific resistivity in the $550{ }^{\circ} \mathrm{C}$ RTA-treated films as a function of the applied voltage is connected with the smaller increase of the current density in the $550{ }^{\circ} \mathrm{C}$ RTA films.

In order to elucidate the role of deep levels in the $\mathrm{ZnO}: \mathrm{N}$ energy gap, we further measured manually, pointbypoint, the I-V characteristics of the MIS structures with $\mathrm{ZnO}: \mathrm{N}$ films. For these experiments, we chose the sample series 2.1-2.3 with maximal concentration of nitrogen in the $\mathrm{ZnO}$ film, expecting a larger effect of $\mathrm{N}$ doping on the electrical characteristics.

The room-temperature I-V characteristics of the MIS structure with $\mathrm{ZnO}: \mathrm{N}$ films deposited at $\mathrm{Ar}: \mathrm{O}_{2}: \mathrm{N}_{2}=50: 10: 40$ (sample 2.1) (a) and after RTA at $550{ }^{\circ} \mathrm{C}$ (sample 2.3) (b) are presented in Figure 5. To reveal the participation of deep levels in the $\mathrm{ZnO}$ energy gap, two-stage I-V measurements were performed. For the as-deposited n-type $\mathrm{ZnO}$ films of sample 2.1 (Figure 5a), the initial stage was measured in 20-25min increments starting from zero up to the maximal applied voltage, $\mathrm{V}_{\mathrm{a}}$, and the second, return stage was carried out immediately after the initial one, down from $V_{a}$ to zero also in 20-25min increments. The corresponding I-V curves in the reverse direction are given as an inset in Figure $5 \mathrm{a}$. The considerable asymmetry between the currents at positive and negative voltage values confirmed the formation of the $\mathrm{n}-\mathrm{ZnO}: \mathrm{N}-\mathrm{p}-\mathrm{Si}$ heterojunction. The forward current in the return stage was higher than the forward current in the initial stage, resulting in a counterclockwise hysteresis in the measured I-V curves. Some of the electrons injected into the $\mathrm{ZnO}$ film during the initial stage were captured at deep levels with time constants higher than the time needed for measuring the initial stage, and their release during the return stage led to the observed excess, higher forward current in the return stage. Thus, the hysteresis in the I-V characteristics indicates that deep levels in the $\mathrm{ZnO}$ energy gap take part in the charge transport mechanism through the n-ZnO:N films. 

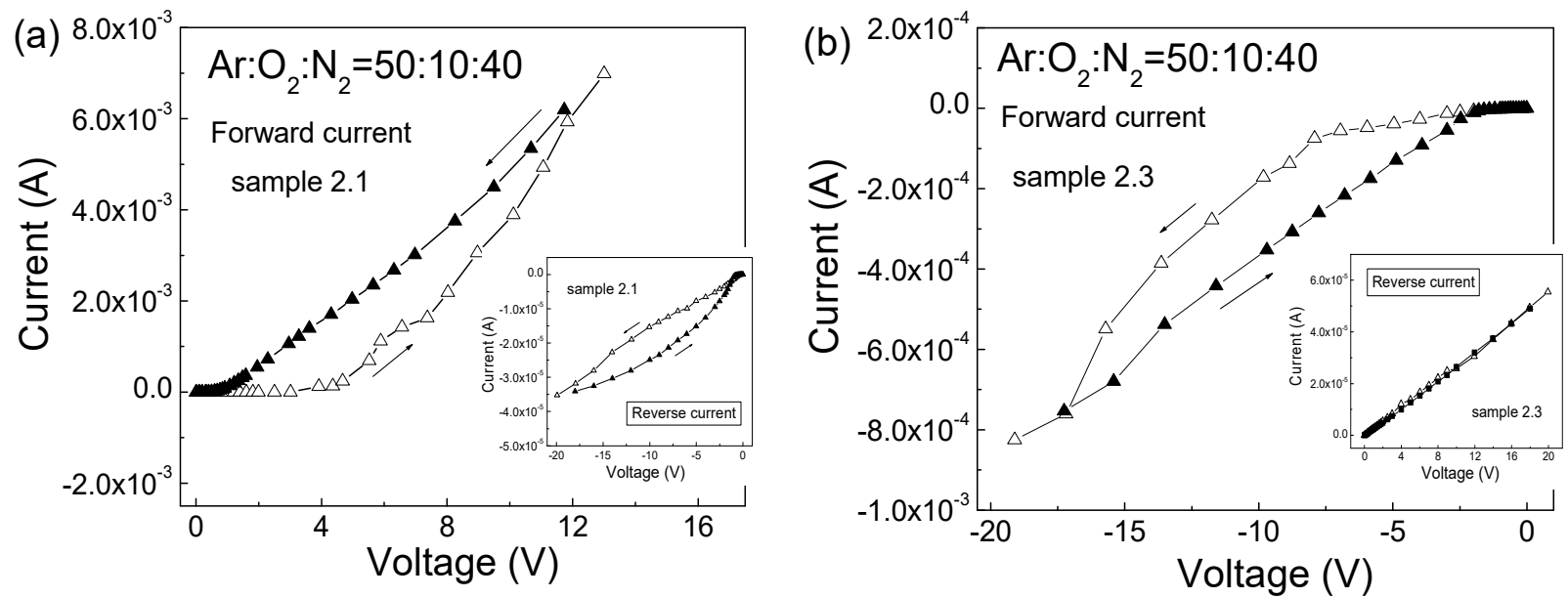

Figure 5. Room temperature I-V characteristics of MIS structures with $\mathrm{ZnO}: \mathrm{N}$ films, deposited at Ar: $\mathrm{O}_{2}: \mathrm{N}_{2}=50: 10: 40$ (sample 2.1) (a) and after RTA at $550{ }^{\circ} \mathrm{C}$ (sample 2.3) (b). The initial and return stages of the I-V measurements are denoted with empty and full triangles, respectively. The corresponding $\mathrm{I}-\mathrm{V}$ curves in the reverse direction are given as insets.

The forward I-V characteristics of the MIS structures with $\mathrm{ZnO}: \mathrm{N}$ films annealed at $550{ }^{\circ} \mathrm{C}$ (sample 2.3) are shown in Figure 5b, withthe corresponding I-V curves in reverse direction are given as inset. As expected, the forward current was with negative voltages applied to the Al-dot contact on the $\mathrm{ZnO}: \mathrm{N}$ surface. As shown in Figure 5b, the forward current in the return stage was also higher than the forward current in the initial stage, leading to the appearance of counterclockwise hysteresis in the forward I-V characteristics. This counterclockwise hysteresis shown in Figure $5 b$, as the one in Figure $5 a$, also confirms that the deep levels in the $\mathrm{ZnO}$ energy gap take part in the charge transport mechanism in the p-ZnO:N films.

The room-temperature dependences of $\ln (\mathrm{J})$ versus $\ln |\mathrm{V}|$ in the forward direction and in the initial stage are presented in Figure 6. For the MIS structures with as-deposited $\mathrm{ZnO}: \mathrm{N}$ films, the slope of the plots is about 8 in the dominant parts of the plots and, around 2 for the other parts. This means that the charge transport in these $\mathrm{ZnO}: \mathrm{N}$ films is carried out via deep levels in the $\mathrm{ZnO}$ energy gap. This transport mechanism is described as trap charge limited current (TCLC) (see for example [48]) or trap-assisted space charge limited current (see for example [49]). For the MIS structures with $550{ }^{\circ} \mathrm{CRT}$-treated $\mathrm{ZnO}: \mathrm{N}$ films, the slope of the $\ln J$ versus $\ln |\mathrm{V}|$ plot (Figure 6) is around 2.5 in the range of 2-18 V. Since this slope is also higher than 2, this means that the charge transport in the p-type $\mathrm{ZnO}: \mathrm{N}$ is also carried out via deep levels in the $\mathrm{ZnO}$ energy gap.

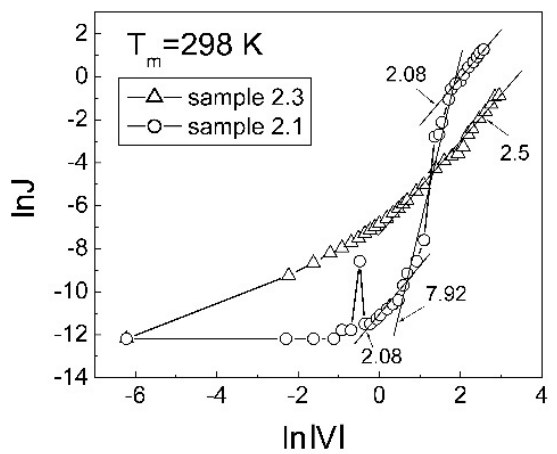

Figure 6. Logarithm of room-temperature forward current density as a function of logarithm absolute voltage for the MIS structures with ZnO:N films, deposited at $\mathrm{Ar}_{2} \mathrm{O}_{2}: \mathrm{N}_{2}=50: 10: 40$ (sample 2.1) and after RTA at $550{ }^{\circ} \mathrm{C}$ (sample 2.3). 
The AC conductance, $\mathrm{G}_{\mathrm{m}}$, of these $\mathrm{ZnO}: \mathrm{N}$ films, measured in the $0.5-500 \mathrm{kHz}$ test frequency range, is plotted in Figure 7 as $\ln G_{m}$ against $\ln \omega$, where $\omega$ is the angular frequency. The slope of the plot for the as-deposited $\mathrm{n}-\mathrm{ZnO}: \mathrm{N}$ film (sample 2.1) is equal to 0.66 . This value is close to the most widespread value 0.7 of the power exponent in the Jonscher universal power law for AC conductance in the case of hopping or tunneling of charge carriers via deep levels near to the Fermi level in the semiconductor energy gap [50]. For the annealed p-ZnO:N films (sample 2.3), the slope of this plot is equal to 0.24.

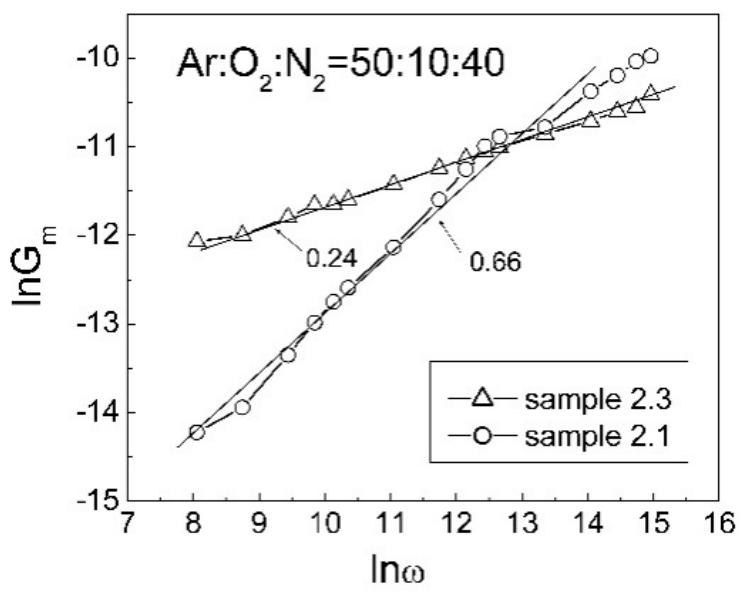

Figure 7. Logarithm of AC conductance, $G_{m}$, versus logarithm of angular frequency, $\omega$, of MIS structures with $\mathrm{ZnO}: \mathrm{N}$ films deposited at $\mathrm{Ar}: \mathrm{O}_{2}: \mathrm{N}_{2}=50: 10: 40$ (sample 2.1) and after RTA at $550{ }^{\circ} \mathrm{C}$ (sample 2.3).

In order to reveal the character of the charge transport mechanism through the $\mathrm{ZnO}: \mathrm{N}$ film, current-voltage measurements must be done at different temperatures. In Figure 8a, the I-V characteristics of the MIS structure with as-deposited n-ZnO:N, measured at 298 and $77 \mathrm{~K}$, are given as the logarithm of the forward current density versus applied voltage. The averaged current density measured at $298 \mathrm{~K}$ under high applied voltages was 2.53 times higher than the current density measured at $77 \mathrm{~K}$. Using the expression $\ln \left(\mathrm{J}_{298} / \mathrm{J}_{77}\right)=\left(\mathrm{q} \varphi_{\mathrm{a}} / \mathrm{k}\right)(1 / 77-1 / 298)$, the effective activation energy, $\mathrm{q} \varphi_{\mathrm{a}}$, of these current densities was estimated. For the as-deposited n-ZnO: $\mathrm{N}$ film, it was equal to $\mathrm{q}_{\mathrm{a}}=8.3 \mathrm{meV}$. This small $\mathrm{q} \varphi_{\mathrm{a}}$ value indicates that the current in this film was carried out predominantly by electron tunneling from the occupied deep level to the nearest unoccupied one in the $\mathrm{ZnO}$ energy gap. The current at $77 \mathrm{~K}$ was carried out by intertrap tunneling mechanism [43]. The measured excess current at $298 \mathrm{~K}$ is a consequence of the appearance of thermally activated carrier hopping in these $\mathrm{ZnO}: \mathrm{N}$ films at temperatures higher than $77 \mathrm{~K}$ [51].

a)

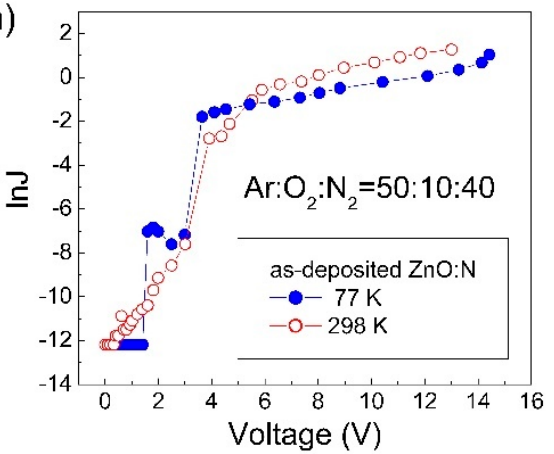

b)

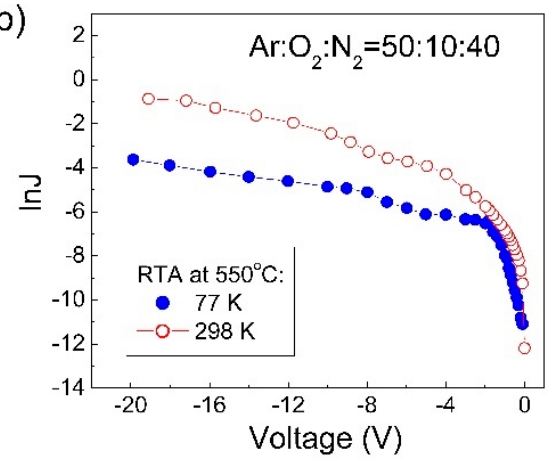

Figure 8. lnJ versus V characteristics, measured at 298 and $77 \mathrm{~K}$, of MIS structures with ZnO:N films deposited at $\mathrm{Ar}: \mathrm{O}_{2}: \mathrm{N}_{2}=50: 10: 40$ (sample 2.1) (a) and after RTA at $550{ }^{\circ} \mathrm{C}$ (sample 2.3) (b). 
In the case of intertrap tunneling, the current density J is given by

$$
\mathrm{J}=\mathrm{J}_{0} \sinh \left[\mathrm{B}\left(\mathrm{V}-\mathrm{V}_{\mathrm{fb}}\right)\right]
$$

where $\mathrm{J}_{0}=2 \mathrm{q} v\left\{\exp \left[-2\left(2 \mathrm{~m}^{*} \mathrm{q}\right)^{1 / 2} \varphi_{\mathrm{t}}{ }^{1 / 2} \mathrm{w} / \hbar\right]\right\} / \mathrm{w}^{2}$ and $\mathrm{B}=\left(2 \mathrm{~m}^{*} \mathrm{q}\right)^{1 / 2} \mathrm{w}^{2} / \hbar \varphi_{\mathrm{t}}{ }^{1 / 2} \mathrm{~d}_{\mathrm{f}}[52] ; \mathrm{w}$ is the mean distance between deep levels situated around the quasi-Fermi level; $v$ is the electron attempt to escape frequency from deep levels; and $\mathrm{q} \varphi_{\mathrm{t}}$ is the energy position of deep levels in the $\mathrm{ZnO}$ energy gap. The electron effective mass, $\mathrm{m}_{\mathrm{n}}{ }^{*}$ for $\mathrm{n}$-type $\mathrm{ZnO}$ is taken as equal to $0.23 \mathrm{me}_{\mathrm{e}}$ [53]. The electron attempts to escape frequency, $v=8.54 \times 10^{12} \mathrm{~s}^{-1}$, is estimated from the relation $\mathrm{h} v=\mathrm{kT}_{\mathrm{D}}$ [54], where the Debye temperature, $\mathrm{T}_{\mathrm{D}}$, for wurtzite $\mathrm{ZnO}$ is $410 \mathrm{~K}$ [55], and all other symbols have their common meaning. From Equation (1) it follows that the values of $\mathrm{w}$ and $\mathrm{q} \varphi_{\mathrm{t}}$ can be determined from the slope of the plot lnJ versus $\mathrm{V}$ and the intersection of the extension of this plot toward the $\ln J$ axis at $\mathrm{V}=0$. These values of $\mathrm{w}$ and $\mathrm{q} \varphi_{\mathrm{t}}$ determined from the lnJ-V plot in Figure $8 \mathrm{a}$ at $77 \mathrm{~K}$ were $4.71 \times 10^{-7} \mathrm{~cm}$ and $1.48 \mathrm{eV}$, respectively. The density of deep levels $\mathrm{N}_{\mathrm{t}}$ in the $\mathrm{ZnO}$ energy gap was estimated by the expression $\mathrm{N}_{\mathrm{t}}=1 / \mathrm{w}^{3}$ and it was equal to $\mathrm{N}_{\mathrm{t}}=9.62 \times 10^{18} \mathrm{~cm}^{-3}$. Because of the energy position of deep levels is $\mathrm{q} \varphi_{\mathrm{t}}=1.48 \mathrm{eV}$, the position of electron quasi-Fermi level in these $\mathrm{n}-\mathrm{ZnO}$ MIS structures was $0.12 \mathrm{eV}$ above the middle of the $\mathrm{ZnO}$ energy gap.

When the concentration of deep levels is known, one may calculate the mobility $\mu_{t}$ for this intertrap tunneling charge transport by the relation $\mu_{\mathrm{t}}=\mathrm{J} /\left(\mathrm{qN} \mathrm{N}_{\mathrm{t}} \mathrm{E}\right)$, where $\mathrm{J}$ is the current density at the applied voltage $\mathrm{V}$ and $\mathrm{E}$ is the electric field across the $\mathrm{ZnO}$ film. In the accumulation conditions at the $\mathrm{ZnO} / \mathrm{Si}$ interface, $\mathrm{E}$ is given by $\mathrm{V} / \mathrm{d}_{\mathrm{f}}$, where $\mathrm{d}_{\mathrm{f}}$ is the $\mathrm{ZnO}$ film thickness. The calculated low value of $\mu_{\mathrm{t}}=1.04 \times 10^{-6} \mathrm{~cm}^{2} \mathrm{~V}^{-1} \mathrm{~s}^{-1}$ is characteristic for charge transport via deep levels in the semiconductor band gap.

The excess of the current at $298 \mathrm{~K}$ over that at $77 \mathrm{~K}$ (Figure 8a) is evidence for thermally activated carrier hopping in these n-ZnO MIS structures. N.F. Mott [51] has proposed that in the case of variable range hopping (VRH), the temperature-dependent conductivity can be expressed by $\sigma(T)=\sigma_{0} \exp \left\{-\left(\mathrm{T}_{0} / \mathrm{T}\right)^{1 / 4}\right\}$, where $\sigma$ is the specific conductivity and $\mathrm{T}_{0}$ is the characteristic temperature. This dependence is appropriate for the Mott VRH in $\mathrm{ZnO}$ [56-58]. One may calculate the value of characteristic temperature $\mathrm{T}_{0}$ by using the expression $\ln \left(\mathrm{J}_{298} / \mathrm{J}_{77}\right)=\mathrm{T}_{0}{ }^{1 / 4}\left[1 /(77)^{1 / 4}-1 /(298)^{1 / 4}\right]$, where the current density is averaged over high applied voltages. For the as-deposited n-ZnO MIS structures (Figure 8a) this value was $\mathrm{T}_{0}=8.45 \times 10^{3} \mathrm{~K}$.

The localization length, Bohr radius, $\mathrm{a}_{\mathrm{B}, \mathrm{ZnO}}$, of the localized states in the $\mathrm{ZnO}$ energy gap is given by the expression $\mathrm{a}_{\mathrm{B}, \mathrm{ZnO}}=\left(4 \pi \varepsilon \mathrm{ZnO} \hbar^{2}\right) /\left(\mathrm{m}^{*} \mathrm{q}^{2}\right)$, where $\varepsilon_{\mathrm{ZnO}}$ is the dielectric constant of $\mathrm{ZnO}, \mathrm{m}^{*}$ is the effective electron mass in $\mathrm{ZnO}$, and other symbols have their usual meanings. In the corresponding $1 \mathrm{MHz} \mathrm{C}-\mathrm{V}$ curve of sample 2.1 (not shown in this paper), the measured maximal capacitance value in the accumulation regime was equal to $C_{\max }=98 \mathrm{pF}$. As $\mathrm{C}_{\max }$ is expressed by $\mathrm{C}_{\max }=\varepsilon \varepsilon_{0} \mathrm{~S} / \mathrm{d}_{\mathrm{f}}$, the dielectric constant $\varepsilon_{\mathrm{ZnO}}$ of the ZnO:N film was determined as $\varepsilon_{\mathrm{ZnO}}=\varepsilon \varepsilon_{0}=1.03 \times 10^{-12} \mathrm{~F} / \mathrm{cm}$. Knowing $\varepsilon_{\mathrm{ZnO}}$ and $\mathrm{m}_{\mathrm{n}}{ }^{*}=0.23 \mathrm{~m}_{\mathrm{e}}$ [53] quantities, the calculated value of $\mathrm{a}_{\mathrm{B}, \mathrm{ZnO}}$ was equal to $\mathrm{a}_{\mathrm{B}, \mathrm{ZnO}}=2.674 \times 10^{-7} \mathrm{~cm}$.

The density of localized states, $\mathrm{N}(\varepsilon)$, in the case of hopping mechanism is given by the expression $\mathrm{N}(\varepsilon)=16 \alpha^{3} / \mathrm{kT}_{0}$, where the decay constant $\alpha$ is the inverse of the Bohr radius $\left(\alpha=1 / \mathrm{a}_{\mathrm{B}, \mathrm{ZnO}}\right)$. The numerical factor 16 is taken from Ambegaokar et al. [59]. With $\alpha=3.74 \times 10^{6} \mathrm{~cm}^{-1}$ and $\mathrm{T}_{0}=8.449 \times 10^{3} \mathrm{~K}$ the calculated value of $\mathrm{N}(\varepsilon)$ was equal to $1.15 \times 10^{21} \mathrm{~cm}^{-3} \cdot \mathrm{eV}^{-1}$. When $\mathrm{N}(\varepsilon)$ is known, the most probable hopping distance $\mathrm{R}_{\mathrm{m}}$ can be estimated by the expression $R_{m}=(9 / 8 \pi \alpha \mathrm{N}(\varepsilon) \mathrm{kT})^{1 / 4}[60,61]$. At the temperature of $187.5 \mathrm{~K}$, taken as the middle value of temperature range of $77-298 \mathrm{~K}, \mathrm{R}_{\mathrm{m}}$ was calculated, and it was equal to $R_{m}=2.677 \times 10^{-7} \mathrm{~cm}$. This $R_{m}$ value is practically equal to the localization radius $\mathrm{a}_{\mathrm{B}, \mathrm{ZnO}}=2.67 \times 10^{-7} \mathrm{~cm}$, and it is $14 \%$ higher than the half-distance $\mathrm{w}=2.35 \times 10^{-7} \mathrm{~cm}$ between adjacent deep levels obtained from the I-V measurement at $77 \mathrm{~K}$. The most probable energy difference of deep levels, $\Delta \mathrm{W}$, taking part in the electron hopping is given by $\Delta W=\left(3 / 4 \pi R_{m}{ }^{3} \mathrm{~N}(\varepsilon)\right)[60,61]$. The calculated value of $\Delta \mathrm{W}=10.78 \mathrm{meV}$ for this hopping in the n-ZnO-p-Si MIS structures was close to the effective thermally 
activation energy $\mathrm{q} \varphi_{\mathrm{a}}=8.3 \mathrm{meV}$ in the as-deposited $\mathrm{n}-\mathrm{ZnO}$ films. Therefore, in addition to temperature-independent intertrap tunneling, thermally activated hopping also took place in these n-type $\mathrm{ZnO}$ films in the temperature range of 77-298 K.

In Figure 8b, the forward I-V characteristics, measured at 298 and $77 \mathrm{~K}$, of the MIS structures with $\mathrm{ZnO}: \mathrm{N}$ films after RTA at $550{ }^{\circ} \mathrm{C}$ (sample 2.3) are given as the logarithm of the current density versus applied voltage. The averaged current density measured at $298 \mathrm{~K}$ under high applied voltage was 17.21 times higher than the current density measured at $77 \mathrm{~K}$. The effective activation energy of the current densityof this p-ZnO:N film, obtained from the expression $\ln \left(\mathrm{J}_{298} / \mathrm{J}_{77}\right)=\left(\mathrm{q} \varphi_{\mathrm{a}} / \mathrm{k}\right)(1 / 77-1 / 298)$ was equal to $\mathrm{q} \varphi_{\mathrm{a}}=25.46 \mathrm{meV}$. This value shows that the current in these $\mathrm{p}-\mathrm{ZnO}: \mathrm{N}$ films was also carried out predominantly by tunneling of holes from the occupied deep level to the nearest unoccupied one in the $\mathrm{ZnO}: \mathrm{N}$ energy gap. Because of that, at $77 \mathrm{~K}$ the current density $\mathrm{J}$ is also given by the equation (1), where the electron effective mass, $m_{n}{ }^{*}=0.23 m_{e}$, is replaced with the hole effective mass, $\mathrm{m}_{\mathrm{h}}{ }^{*}=0.59 \mathrm{~m}_{\mathrm{e}}$ [62].

The values of $\mathrm{q} \varphi_{\mathrm{t}}$ and $\mathrm{w}$, calculated from the slope of the plot $\ln$ J versus $\mathrm{V}$ in Figure $8 \mathrm{~b}$ and the intersection of the extension of this plot toward $\ln \mathrm{J}$ axis at $\mathrm{V}=0$, were $\mathrm{q} \varphi_{\mathrm{t}}=1.27 \mathrm{eV}$ and $\mathrm{w}=3.724 \times 10^{-7} \mathrm{~cm}$, respectively. Under high forward bias the concentration of injected holes in the annealed at $550{ }^{\circ} \mathrm{C} \mathrm{p}-\mathrm{ZnO}$ film was equal to $\mathrm{N}_{\mathrm{t}}=1 / \mathrm{w}^{3}=1.94 \times 10^{19} \mathrm{~cm}^{-3}$. Taking into account that our previous EDX studies have shown a nitrogen/oxygen ratio of $1 / 8$ in both RF-sputtered and annealed $\mathrm{ZnO}: \mathrm{N}$ films [25], the total concentration of nitrogen in the $550{ }^{\circ} \mathrm{C}$ RTA p-ZnO film (sample 2.3) was $1.82 \times 10^{21} \mathrm{~cm}^{-3}$. The comparison between the concentration of acceptor deep levels $\left(\mathrm{N}_{\mathrm{t}}=1.94 \times 10^{19} \mathrm{~cm}^{-3}\right)$ with the total concentration of $\mathrm{N}$ atoms incorporated into $\mathrm{ZnO}: \mathrm{N}$ films $\left(1.82 \times 10^{21} \mathrm{~cm}^{-3}\right)$ shows that less than $1 \%$ of acceptor levels were not compensated. Because of this strong charge compensation, it is difficult to achieve an increase in the conductivity of $\mathrm{ZnO}$ by introducing a larger amount of nitrogen into a $\mathrm{ZnO}: \mathrm{N}$ film.

Assuming that temperature-dependent current in these p-type $\mathrm{ZnO}: \mathrm{N}$ films is also governed by the Mott VRH [51], the characteristic temperature $\mathrm{T}_{0}$ obtained from the relation $\ln \left(\mathrm{J}_{298} / \mathrm{J}_{77}\right)=\mathrm{T}_{0}{ }^{1 / 4}\left[1 /(77)^{1 / 4}-1 /(298)^{1 / 4}\right]$ was equal to $\mathrm{T}_{0}=7.44 \times 10^{5} \mathrm{~K}$. The values of the Bohr radius $\mathrm{a}_{\mathrm{B}, \mathrm{ZnO}}$, the decay constant $\alpha$, the density of localized states, $\mathrm{N}(\varepsilon)$, the most probable hopping distance, $\mathrm{R}_{\mathrm{m}}$, and the most probable hopping energy difference, $\Delta W$, were calculated in the same way as the corresponding parameters for the n-type $\mathrm{ZnO}: \mathrm{N}$ films. The obtained values were, respectively, $\mathrm{a}_{\mathrm{B}, \mathrm{ZnO}}=1.042 \times 10^{-7} \mathrm{~cm}$, $\alpha=9.59 \times 10^{6} \mathrm{~cm}^{-1}$, and $\mathrm{N}(\varepsilon)=2.2 \times 10^{20} \mathrm{~cm}^{-3} \cdot \mathrm{eV}^{-1}$, and at $187.5 \mathrm{~K}$ the $\mathrm{R}_{\mathrm{m}}$ and $\Delta \mathrm{W}$ values were $3.2 \times 10^{-7} \mathrm{~cm}$ and $33.07 \mathrm{meV}$, respectively. These results reveal that in the p-type $\mathrm{ZnO}$ films, the most probable hopping distance $\mathrm{R}_{\mathrm{m}}$ was about three times larger than the Bohr radius $\mathrm{a}_{\mathrm{B}, \mathrm{ZnO}}$ and this relation confirms that Mott variable range hopping of holes occurred in these p-type $\mathrm{ZnO}: \mathrm{N}$ films. Therefore, the additional current at $298 \mathrm{~K}$ compared to that at $77 \mathrm{~K}$ in these p-type $\mathrm{ZnO}: \mathrm{N}$ films was carried out by charge carrier hopping, close to the Fermi or the quasi-Fermi level in the $\mathrm{ZnO}: \mathrm{N}$ energy gap.

For better insight, the above calculated charge transport parameters of the intertrap tunneling and variable range hopping mechanism in $\mathrm{ZnO}: \mathrm{N}$ films deposited at a gas ratio of Ar: $\mathrm{O}_{2}: \mathrm{N}_{2}=50: 10: 40$ (sample 2.1) and treated by RTA at $550{ }^{\circ} \mathrm{C}$ (sample 2.1) are summarized in Table 4. 
Table 4. Intertrap tunneling and variable range hopping parameters of $\mathrm{ZnO}: \mathrm{N}$ films deposited at gas ratio of $\mathrm{Ar}: \mathrm{O}_{2}: \mathrm{N}_{2}=50: 10: 40$ (sample 2.1) and treated by RTA at $550{ }^{\circ} \mathrm{C}$ (sample 2.1): $\mathrm{q} \varphi_{\mathrm{a}}$-effective thermally activation energy; $\mathrm{w}$-mean distance between deep levels; $\mathrm{q} \varphi_{\mathrm{t}}$ and $\mathrm{N}_{\mathrm{t}}$ - energy position and density of deep levels, respectively, in the $\mathrm{ZnO}$ energy gap; $\mathrm{T}_{0}$-characteristic temperature; $\mathrm{a}_{\mathrm{B}, \mathrm{ZnO}}$ - Bohr radius of the localized states in the $\mathrm{ZnO}$ energy gap; $\mathrm{N}(\varepsilon)$ - density of localized states; $\mathrm{R}_{\mathrm{m}}$ and $\Delta \mathrm{W}$-most probable hopping distance and energy difference of deep levels, respectively.

\begin{tabular}{|c|c|c|}
\hline Parameters & $\begin{array}{l}\text { As-Deposited } \\
\text { ZnO:N }\end{array}$ & After RTA at $550{ }^{\circ} \mathrm{C}$ \\
\hline \multicolumn{3}{|c|}{ Intertrap tunneling } \\
\hline $\mathrm{q} \varphi_{\mathrm{a}}(\mathrm{meV})$ & 8.3 & 25.46 \\
\hline $\mathrm{w}(\mathrm{cm})$ at $77 \mathrm{~K}$ & $4.70 \times 10^{-7}$ & $3.724 \times 10^{-7}$ \\
\hline $\mathrm{q} \varphi_{\mathrm{t}}(\mathrm{eV})$ at $77 \mathrm{~K}$ & 1.48 & 1.27 \\
\hline $\mathrm{N}_{\mathrm{t}}\left(\mathrm{cm}^{-3}\right)$ at $77 \mathrm{~K}$ & $9.62 \times 10^{18}$ & $1.94 \times 10^{19}$ \\
\hline \multicolumn{3}{|c|}{ Variable range hopping } \\
\hline $\mathrm{T}_{0}(\mathrm{~K})$ & $8.45 \times 10^{3}$ & $7.44 \times 10^{5}$ \\
\hline $\mathrm{a}_{\mathrm{B}, \mathrm{ZnO}}(\mathrm{cm})$ & $2.67 \times 10^{-7}$ & $1.04 \times 10^{-7}$ \\
\hline $\mathrm{N}(\varepsilon)\left(\mathrm{cm}^{-3} \cdot \mathrm{eV}^{-1}\right)$ & $1.15 \times 10^{21}$ & $2.2 \times 10^{20}$ \\
\hline $\mathrm{R}_{\mathrm{m}}(\mathrm{cm})$ at $187.5 \mathrm{~K}$ & $2.677 \times 10^{-7}$ & $3.2 \times 10^{-7}$ \\
\hline$\Delta \mathrm{W}(\mathrm{meV})$ at $187.5 \mathrm{~K}$ & 10.78 & 33.07 \\
\hline
\end{tabular}

The decrease of the $\mathrm{ZnO}$ band gap density of localized states from $\mathrm{N}(\varepsilon)=1.15 \times 10^{21} \mathrm{~cm}^{-3} \mathrm{eV}^{-1}$ for the as-deposited ZnO:N (sample 2.1) to $\mathrm{N}(\varepsilon)=2.2 \times 10^{20} \mathrm{~cm}^{-3} \mathrm{eV}^{-1}$ for the p-ZnO:N after $550{ }^{\circ} \mathrm{C}$ RTA (sample 2.3) correlates well with the observed decrease in the slope values of $\ln \mathrm{G}_{\mathrm{m}}$ versus $\ln \omega$ plots (Figure 7) from 0.66 to 0.24 , respectively. The decrease of the density of localized states in the $\mathrm{ZnO}$ bandgap by the $550{ }^{\circ} \mathrm{C}$ RTA is evidence that the concentration of donor-like defects decreased during this treatment. The densities of localized states $\mathrm{N}(\varepsilon)$ given in Table 4 are within the range of $9.93 \times 10^{19}-2.08 \times 10^{22} \mathrm{~cm}^{-3} \mathrm{eV}^{-1}$ reported for VRH conduction in n-type polycrystalline ZnO films [63]. Values of $\mathrm{N}(\varepsilon)=2 \times 10^{20} \mathrm{~cm}^{-3} \mathrm{eV}^{-1}$ and $\Delta W=29 \mathrm{meV}$, close to ours, for the densities of localized states and corresponding characteristic energies, respectively, have been obtained from the current-voltage characteristics of amorphous $\mathrm{ZnON}$ thin film transistors [64].

The established transformation of n-type conduction to p-type in the studied ZnO:N films viaannealing the samples at $550{ }^{\circ} \mathrm{C}$ suggests that if the deposition could be accomplished at such elevated temperatures as $550{ }^{\circ} \mathrm{C}$, the density of localized states could be reduced below $\mathrm{N}(\varepsilon)=2.2 \times 10^{20} \mathrm{~cm}^{-3} \cdot \mathrm{eV}^{-1}$, as was obtained in the $550{ }^{\circ} \mathrm{C}$ RTA-treated $\mathrm{ZnO}: \mathrm{N}$ films. In this way, it would be possible to obtain nitrogen-doped $\mathrm{ZnO}$ films with weaker $\mathrm{N}$-acceptor self-compensation and a smaller density of localized states in the p-type $\mathrm{ZnO}$ band gap than that we observed herein.

\section{Conclusions}

Nitrogen-doped $\mathrm{ZnO}$ thin films were deposited onto Si substrates by RF magnetron sputtering in nitrogen-containing ambient gas, followed by rapid thermal annealing at $400{ }^{\circ} \mathrm{C}$ and $550{ }^{\circ} \mathrm{C}$ in nitrogen. Raman and PL spectroscopic analyses revealed defects due to $\mathrm{O}$ and $\mathrm{Zn}$ vacancies and interstitials, which are related to carrier traps in the $\mathrm{ZnO}: \mathrm{N}$ films.

Detailed analyses of the I-V characteristics of the MIS structures with the ZnO:N films revealedn-type conduction in both as-deposited and annealed at $400{ }^{\circ} \mathrm{C} \mathrm{ZnO}: \mathrm{N}$ films. The reason for n-type conductivity in these $\mathrm{ZnO}: \mathrm{N}$ films is a result of the self-compensation of the $\mathrm{N}$-acceptor levels by donor-like defects generated during $\mathrm{N}$ doping. RTA at $550{ }^{\circ} \mathrm{C}$ decrease the concentration of donor-like defects below the concentration of $\mathrm{N}$ acceptors and, as a consequence, the n-type $\mathrm{ZnO}: \mathrm{N}$ films transformed into p-type $\mathrm{ZnO}: \mathrm{N}$ ones. Repeated measurements after a year proved that the resulting conduction-type transformation at the annealing stage at $550{ }^{\circ} \mathrm{C}$ is a stable process. 
The observed counterclockwise hysteresis in the measured point-by-point I-V characteristics of both $\mathrm{n}$ - and $\mathrm{p}$ type $\mathrm{ZnO}: \mathrm{N}$ films confirms the presence of deep levels in the $\mathrm{ZnO}$ energy gap which participate in the charge transport through these $\mathrm{ZnO}: \mathrm{N}$ films. The slope of the $\ln$ J versus $\ln \mathrm{V}$ plots reveals that the current in both n- and p-type $\mathrm{ZnO}: \mathrm{N}$ films is trap charge limited current (TCLC), while the slope of the $\ln G_{m}$ versus $\ln \omega$ plots confirms the tunneling or hopping of charge carriers via deep levels in the $\mathrm{ZnO}$ energy gap.

At $77 \mathrm{~K}$, the current in both $\mathrm{n}$ - and p-type $\mathrm{ZnO}: \mathrm{N}$ films is carried out by intertrap tunneling via deep levels in the $\mathrm{ZnO}$ energy gap. The higher forward averaged current density at $298 \mathrm{~K}$ than that measured at $77 \mathrm{~K}$ reveals additional thermally activated variable range carrier hopping in these $\mathrm{ZnO}: \mathrm{N}$ films.

Author Contributions: Formal analysis, investigation, writing-original draft preparation, S.S. and M.N.; conceptualization, investigation, writing-original draft preparation, writing-review and editing, A.S.; formal analysis, investigation, D.S. and I.S., formal analysis, writing-review and editing M.A.; visualization, E.A. and M.M.; conceptualization, writing-review and editing, data curation, project administration, funding acquisition, M.G. All authors have read and agreed to the published version of the manuscript.

Funding: This research was funded by the Romanian National Authority for Scientific Research on Innovation, grant number PN-III-P2-2.1-PED-2019-2073. Part of this work was supported by the project "Materials and Processes for Energy and Environment Applications-AENAO" (MIS 5002556) co-financed by Greece and the European Regional Development Fund.

Institutional Review Board Statement: Not applicable.

Informed Consent Statement: Not applicable.

Data Availability Statement: The data presented in this study are available on request from the corresponding author.

Acknowledgments: The paper was carried out within the research program "Science of Surfaces and Thin Layers" of the "Ilie Murgulescu" Institute of Physical Chemistry. The support of the Romanian Government that allowed for the acquisition of the research infrastructure under POSCCE O 2.2.1 project INFRANANOCHEM-No. 19/01.03.2009 and the support of inter-academic exchange program between the Romanian and Bulgarian Academies Collaboration Agreements are gratefully acknowledged.

Conflicts of Interest: The authors declare that they have no conflict of interest.

\section{References}

1. Jellison, G.E.; Boatner, L.A. Optical functions of uniaxial ZnO determined by generalized ellipsometry. Phys. Rev. B 1998, 58, 3586-3589. [CrossRef]

2. Han, C.; Duan, L.; Zhao, X.; Hu, Z.; Niu, Y.; Geng, W. Effect of Fe doping on structural and optical properties of ZnO films and nanorods. J. Alloy. Compd. 2019, 770, 854-863. [CrossRef]

3. Przezdziecka, E.; Guziewicz, E.; Witkowski, B.S. Photoluminescence investigation of the carrier recombination processes in N-doped and undoped ZnO ALD films grown at low temperature. J. Lumin. 2018, 198, 68-76. [CrossRef]

4. Xu, W.Z.; Ye, Z.Z.; Zeng, Y.J.; Zhu, L.P.; Zhao, B.H.; Jiang, L.; Lu, J.G.; He, H.P.; Zhang, S.B. ZnO light-emitting diode grown by plasma-assisted metal organic chemical vapor deposition. Appl. Phys. Lett. 2006, 88, 173506. [CrossRef]

5. Jee, S.W.; Park, S.J.; Kim, J.; Park, Y.C.; Choi, J.H.; Jeong, J.H.; Lee, J.H. Efficient three-dimensional nanostructured photoelectric device by Al-ZnO coating on lithography-free patterned Si nanopillars. Appl. Phys. Lett. 2011, 99, 053118. [CrossRef]

6. Socol, G.; Axente, E.; Ristoscu, C.; Sima, F.; Popescu, A.; Stefan, N.; Mihailescu, I.N.; Escoubas, L.; Ferreira, J.; Bakalova, S.; et al. Enhanced gas sensing of Au nanocluster -doped or -coated zinc oxide thin films. J. Appl. Phys. 2007, 102, 083103. [CrossRef]

7. Kumar, R.; Al-Dossary, O.; Kumar, G.; Umar, A. Zinc Oxide Nanostructures for NO2 Gas-Sensor Applications: A Review. Nano-Micro Lett. 2015, 7, 97-120. [CrossRef]

8. Mosca, M.; Macaluso, R.; Caruso, F.; Lo Muzzo, V.; Calì, C. The P-Type Doping of ZnO: Mirage or Reality Advances in Semiconductor Research: Physics of Nanosystems, Spintronics and Technological Applications; Nova Science Publishers: New York, NY, USA, 2015; Chapter 12; pp. 245-282.

9. Barnes, T.M.; Olson, K.; Wolden, C.A. On the formation and stability of p-type conductivity in nitrogen-doped zinc oxide. Appl. Phys. Lett. 2005, 86, 112112.

10. Kennedy, O.W.; Coke, M.L.; White, E.R.; Shaffer, M.S.P.; Warburton, P.A. MBE growth and morphology control of ZnO nanobelts with polar axis perpendicular to growth direction. Mater. Lett. 2018, 212, 51-53. [CrossRef] 
11. Li, J.; Wang, J.; Pei, Y.; Wang, G. Research and optimization of ZnO-MOCVD process parameters using CFD and genetic algorithm. Ceram. Int. 2020, 46, 685-695. [CrossRef]

12. Coutancier, D.; Zhang, S.T.; Bernardini, S.; Fournier, O.; Mathieu-Pennober, T.; Donsanti, F.; Tchernycheva, M.; Foldyna, M.; Schneide, N. ALD of ZnO:Ti: Growth Mechanism and Application as an Efficient Transparent Conductive Oxide in Silicon Nanowire Solar Cells. ACS Appl. Mater. Interfaces 2020, 12, 21036-21044. [CrossRef] [PubMed]

13. Dave, P.Y.; Patel, K.H.; Chauhan, K.V.; Chawla, A.K.; Rawal, S.K. Examination of zinc oxide films prepared by magnetron Sputtering. Proc. Technol. 2016, 23, 328-335. [CrossRef]

14. Manikandan, B.; Endo, T.; Kaneko, S.; Murali, K.R.; John, R. Properties of sol gel synthesized ZnO nanoparticles. J. Mater. Sci. 2018, 29, 9474-9485. [CrossRef]

15. Fan, J.C.; Sreekanth, K.M.; Xie, Z.; Chang, S.L.; Rao, K.V. p-Type ZnO materials: Theory, growth, properties and devices". Prog. Mater. Sci. 2013, 58, 874-985. [CrossRef]

16. Wang, Z.; Li, Q.; Yuan, Y.; Yang, L.; Zhang, H.; Liu, Z.; Ouyang, J.; Chen, Q. N doped ZnO (N:ZnO) film prepared by reactive HiPIMS deposition technique. AIP Adv. 2020, 10, 035122. [CrossRef]

17. Hussain, B.; Aslam, A.; Khan, T.M.; Creighton, M.; Zohuri, B. Electron Affinity and Bandgap Optimization of Zinc Oxide for Improved Performance of $\mathrm{ZnO} / \mathrm{Si}$ Heterojunction Solar Cell Using PC1D Simulations. Electronics 2019, 8, 238. [CrossRef]

18. Czternastek, H. ZnO thin films prepared by high pressure magnetron sputtering. Opto-Electron. Rev. 2004, 12, 49-52.

19. Tsay, C.-Y.; Chiu, W.-Y. Enhanced Electrical Properties and Stability of P-Type Conduction in ZnO Transparent Semiconductor Thin Films by Co-Doping Ga and N. Coatings 2020, 10, 1069.

20. Lee, E.-C.; Kim, Y.-S.; Jin, Y.-G.; Chang, K.J. Compensation mechanism for N acceptors in ZnO. Phys. Rev. B 2001, 64, 085120. [CrossRef]

21. Kim, J.; Ji, J.H.; Min, S.W.; Jo, G.H.; Jung, M.W.; Koh, J.H. Enhanced conductance properties of UV laser/RTA annealed Al-doped ZnO thin films. Ceram. Int. 2017, 43, 3900-3904. [CrossRef]

22. Watanabe, F.; Shirai, H.; Fujii, Y.; Hanajiri, T. Rapid thermal annealing of sputter-deposited ZnO/ZnO:N/ZnO multilayered structures. Thin Solid Film. 2012, 520, 3729-3735. [CrossRef]

23. Nicolescu, M.; Anastasescu, M.; Preda, S.; Calderon-Moreno, J.M.; Osiceanu, P.; Gartner, M.; Teodorescu, V.S.; Maraloiu, A.V.; Kampylafka, V.; Aperathitis, E.; et al. Investigation of microstructural properties of nitrogen doped $\mathrm{ZnO}$ thin films formed by magnetron sputtering on silicon substrate. J. Optoelectron. Adv. Mater. 2010, 12, 1045-1051.

24. Nicolescu, M.; Anastasescu, M.; Preda, S.; Calderon-Moreno, J.M.; Osiceanu, P.; Gartner, M.; Teodorescu, V.S.; Maraloiu, A.V.; Kampylafka, V.; Aperathitis, E.; et al. Surface topography and optical properties of nitrogen doped ZnO thin films formed by radio frequency magnetron sputtering on fused silica substrates. J. Optoelectron. Adv. Mater. 2010, 12, 1343-1349.

25. Nicolescu, M.; Anastasescu, M.; Preda, S.; Stroescu, H.; Stoica, M.; Teodorescu, V.S.; Aperathitis, E.; Kampylafka, V.; Modreanu, M.; Zaharescu, M.; et al. Influence of the substrate and nitrogen amount on the microstructural and optical properties of thin r.f.-sputtered ZnO films treated by rapid thermal annealing. Appl. Surf. Sci. 2012, 261, 815-823. [CrossRef]

26. Himmerlich, M.; Koufaki, M.; Ecke, G.; Mauder, C.; Cimalla, V.; Schaefer, J.A.; Kondilis, A.; Pelekanos, N.T.; Modreanu, M.; Krischok, S.; et al. Effect of Annealing on the Properties of Indium-Tin-Oxynitride Films as Ohmic Contacts for GaN-Based Optoelectronic Devices. ACS Appl. Mater. Interfaces 2009, 1, 1451-1456. [CrossRef]

27. Chang, H.T.; Chen, G.J. Influence of nitrogen doping on the properties of $\mathrm{ZnO}$ films prepared by radio-frequency magnetron sputtering. Thin Solid Film. 2016, 618, 84-89. [CrossRef]

28. Kumar, R.R.; Raja Sekhar, M.; Raghvendra, R.L.; Kumar Pandey, S. Comparative studies of ZnO thin films grown by electron beam evaporation, pulsed laser and RF sputtering technique for optoelectronics applications. Appl. Phys. A 2020, 126, 859. [CrossRef]

29. Panda, J.; Sasmal, I.; Nath, T.K. Magnetic and optical properties of Mn-doped ZnO vertically aligned nanorods synthesized by hydrothermal technique. AIP Adv. 2016, 6, 035118. [CrossRef]

30. Cusco, R.; Alarcon-Llado, E.; Ibanez, J.; Artus, L.; Jimenez, J.; Wang, B.; Callahan, M.J. Temperature dependence of Raman scattering in ZnO. Phys. Rev. B Condens. Matter. Mater. Phys. 2007, 75, 165202. [CrossRef]

31. Manjon, F.J.; Mari, B.; Serrano, J.; Romero, A.H. Silent Raman modes in zinc oxide and related nitrides. J. Appl. Phys. 2005, 97, 053516. [CrossRef]

32. Raji, R.; Gopchandran, K.G. ZnO nanostructures with tunable visible luminescence: Effects of kinetics of chemical reduction and annealing. J. Sci. Adv. Mater. Dev. 2017, 2, 51-58. [CrossRef]

33. Musa, I.; Qamhieh, N.; Mahmoud, S.T. Synthesis and dependent photoluminescence property of zinc oxide nanorods. Results Phys. 2017, 7, 3552-3556. [CrossRef]

34. Zerdali, M.; Hamzaoui, S.; Teherani, F.H.; Rogers, D. Growth of ZnO thin film on SiO2/Si substrate by pulsed laser deposition and study of their physical properties. Mater. Lett. 2006, 60, 504-508. [CrossRef]

35. Song, Y.; Zhang, S.; Zhang, C.; Yang, Y.; Lv, K. Raman Spectra and Microstructure of Zinc Oxide irradiated with Swift Heavy Ion. Crystals 2019, 9, 395. [CrossRef]

36. Decremps, F.; Pellicer-Porres, J.; Saitta, A.M.; Chervin, J.C.; Polian, A. High-pressure Raman spectroscopy study of wurtzite ZnO Phys. Rev. B 2002, 65, 092101-092105. [CrossRef]

37. Ng, Z.N.; Chan, K.Y.; Muslimin, S.; Knipp, D. P-Type Characteristic of Nitrogen-Doped ZnO Films. J. Electron. Mater. 2018, 47, 5607-5613. [CrossRef] 
38. Kegel, J.; Laffir, F.R.; Povey, I.M.; Pemble, M.E. Defect-promoted photo-electrochemical performance enhancement of orangeluminescent ZnO nanorod-arrays. Phys. Chem. Chem. Phys. 2017, 19, 12255-12268. [CrossRef] [PubMed]

39. Fatima, A.A.; Devadason, S.; Mahalingam, T. Structural, luminescence and magnetic properties of Mn doped ZnO thin films using spin coating technique. J. Mater. Sci.-Mater. Electron. 2014, 25, 3466-3472. [CrossRef]

40. Ismail, A.; Abdullah, M.J. The structural and optical properties of $\mathrm{ZnO}$ thin films prepared at different RF sputtering power. J. King Saud Univ. Sci. 2013, 25, 209-215. [CrossRef]

41. Kaur, G.; Mitra, A.; Yadav, K.L. Pulsed laser deposited Al-doped ZnO thin films for optical applications. Prog. Nat. Sci.-Mater. Int. 2015, 25, 12-21. [CrossRef]

42. Schmidt, M.; von Wenckstern, H.; Pickenhain, R.; Grundmann, M. On the investigation of electronic defect states in ZnO thin films by space charge spectroscopy with optical excitation. Solid-State Electron. 2012, 75, 48-54. [CrossRef]

43. Look, D.C.; Leedy, K.D.; Vines, L.; Svensson, B.G.; Zubiaga, A.; Tuomisto, F.; Doutt, D.R.; Brillson, L.J. Self-compensation in semiconductors: The Zn vacancy in Ga-doped ZnO. Phys. Rev. B 2011, 84, 115202. [CrossRef]

44. von Wenckstern, H.; Pickenhain, R.; Schmidt, H.; Brandt, M.; Biehne, G.; Lorenz, M.; Grundmann, M. Deep acceptor states in ZnO single crystals. Appl. Phys. Lett. 2006, 89, 092122. [CrossRef]

45. Huang, Z.; Ruan, H.; Zhang, H.; Shi, D.; Li, W.; Qin, G.; Wu, F.; Fang, L.; Kong, C. Investigation of the p-type formation mechanism of nitrogen ion implanted $\mathrm{ZnO}$ thin films induced by rapid thermal annealing. Opt. Mater. Express 2019, 9, 3098. [CrossRef]

46. Zhang, H.; Kong, C.; Li, W.; Qin, G.; Ruan, H.; Tan, M. The formation mechanism and stability of p-type N-doped Zn-rich ZnO films. J. Mater. Sci. Mater. Electron. 2016, 27, 5251-5258. [CrossRef]

47. Kampylafka, V.; Kostopoulos, A.; Modreanu, M.; Schmidt, M.; Gagaoudakis, E.; Tsagaraki, K.; Kontomitrou, V.; Konstantinidis, G.; Deligeorgis, G.; Kiriakidis, G. Long-term stability of transparent n/p ZnO homojunctions grown by rf-sputtering at roomtemperature. J. Mater. 2019, 5, 428-435. [CrossRef]

48. Aksoy, S.; Caglar, Y. Structural transformations of $\mathrm{TiO}_{2}$ films with deposition temperature and electrical properties of nanostructure n- $\mathrm{TiO}_{2}$ / p-Si heterojunction diode. J. Alloy. Compd. 2014, 613, 330-337. [CrossRef]

49. Ghatak, S.; Ghosh, A. Observation of trap-assisted space charge limited conductivity in short channel MoS2 transistor. Appl. Phys. Lett. 2013, 103, 122103. [CrossRef]

50. Jonscher, A.K. The 'Universal' Dielectric Response. Nature 1977, 267, 673-679. [CrossRef]

51. Mott, N.F. Conduction in glasses containing transition metal ions. J. Non-Cryst. Solids 1968, 1, 1-17. [CrossRef]

52. Simeonov, S.; Yourukov, I.; Kafedjiiska, E.; Szekeres, A. Inter-trap tunnelling in thin $\mathrm{SiO}_{2}$ films. Phys. Status Solidi 2004, 201, 2966-2979. [CrossRef]

53. Oshikiri, M.; Imanaka, Y.; Aryasetiawan, F.; Kido, G. Comparison of the electron effective mass of the n-type ZnO in the wurtzite structure measured by cyclotron resonance and calculated from first principle theory. Phys. B Cond. Matter 2001, 298, 472-476. [CrossRef]

54. Mott, N.F.; Algaier, R.S. Localized States in Disordered Lattices. Phys. Status Solidi 1967, 21, 343-356. [CrossRef]

55. Choudhary, K.K. Analysis of temperature-dependent electrical resistivity of ZnO nano-structures. J. Phys. Chem. Solids 2012, 73, 460-464. [CrossRef]

56. Tiwari, A.; Jin, C.; Narayan, J.; Park, M. Electrical transport in ZnO1- $\delta$ films: Transition from band-gap insulator to Anderson localized insulator. J. Appl. Phys. 2004, 96, 3827-3830. [CrossRef]

57. Heluani, S.P.; Braunstein, G.; Villafuerte, M.; Simonelli, G.; Duhalde, S. Electrical conductivity mechanisms in zinc oxide thin films deposited by pulsed laser deposition using different growth environments. Thin Solid Film. 2006, 515, 2379-2386. [CrossRef]

58. Kumar, R.; Khare, N. Temperature dependence of conduction mechanism of ZnO and Co-doped ZnO thin films. Thin Solid Film. 2008, 516, 1302-1307. [CrossRef]

59. Ambegaokar, V.; Halperin, B.I.; Langer, I.S. Hopping Conductivity in Disordered Systems. Phys. Rev. B 1971, 4, 2612-2620. [CrossRef]

60. Ziqan, A.M.; Qasrawi, A.F.; Mohammad, A.H.; Gasanly, N.M. Thermally assisted variable range hopping in $\mathrm{Tl}_{4} \mathrm{~S}_{3} \mathrm{Se}_{\mathrm{crystal}} \mathrm{Bull}$ Mater. Sci. 2015, 38, 593-598. [CrossRef]

61. Mott, N.F.; Davis, E.A. Electronic Processes in Non-Crystalline Materials; Clarendon Press: Oxford, UK, $1971 ;$ p. 437.

62. Norton, D.P.; Heo, Y.W.; Ivill, M.P.; Ip, K.; Pearton, S.J.; Chisholm, M.F.; Steiner, T. ZnO: Growth, doping \& processing. Mater Today 2004, 7, 34-40.

63. Huang, Y.-L.; Chiu, S.-P.; Zhu, Z.-X.; Li, Z.-Q.; Lin, J.-J. Variable-range-hopping conduction processes in oxygen deficient polycrystalline ZnO films. J. Appl. Phys. 2010, 107, 063715. [CrossRef]

64. Lee, S.; Nathan, A.; Ye, Y.; Guo, Y.; Robertson, J. Localized Tail States and Electron Mobility in Amorphous ZnON Thin Film Transistors. Sci. Rep. 2015, 5, 13467. [CrossRef] [PubMed] 